\title{
Dynamic Compressive Properties of Carbon Nanofibers Reinforced Concrete under Impact Load
}

Wei Xia ( $\nabla$ xiaweiafeu@163.com )

Air Force Engineering University

Jinyu Xu

Air Force Engineering University

Liangxue Nie

Air Force Engineering University

\section{Research Article}

Keywords: Carbon nanofibers, Modified concrete, Impact load, Dynamic compressive properties, Strain rate effect

Posted Date: January 22nd, 2021

DOI: https://doi.org/10.21203/rs.3.rs-145789/v1

License: (c) (i) This work is licensed under a Creative Commons Attribution 4.0 International License. Read Full License 


\title{
Dynamic Compressive Properties of Carbon Nanofibers Reinforced Concrete under Impact Load
}

\author{
Wei Xia ${ }^{1}$, Jinyu $\mathrm{Xu}^{1,2}$, Liangxue $\mathrm{Nie}^{1}$ \\ 1. School of Aeronautical Engineering, Air Force Engineering University, Xi'an 710038, China; 2. College of \\ Mechanics and Civil Architecture, Northwest Polytechnic University, Xi'an 710072, China
}

\begin{abstract}
To explore the dynamic compressive properties of carbon nanofibers reinforced concrete (CNFC), a 100mm-diameter Split Hopkinson Pressure Bar (SHPB) was used to carry out the impact compression test respectively on the plain concrete samples and the CNFC samples with different fiber volume fractions (respectively, $0.1 \%, 0.2 \%, 0.3 \%$ and $0.5 \%$ ). On this basis, the change characteristics of concrete at five different strain rate levels in dynamic compressive strength, dynamic compression deformation, impact toughness and dynamic elastic modulus of concrete were compared and analyzed. The results show that the dynamic compressive strength, dynamic compression deformation and impact toughness of concrete are enhanced by carbon nanofibers to varying degrees. Specifically, when the content of carbon nanofibers is $0.3 \%$, its enhancement effect on dynamic compressive strength is the best; when the content of carbon nanofibers is $0.2 \%$, it helps enhance the dynamic elastic modulus of concrete, but other content can only have the opposite effect. The dynamic compressive strength, impact toughness and dynamic elastic modulus of plain concrete and CNFC gradually increase with the increase of strain rate level, indicating the existence of significant linear relationship; although the dynamic peak strain and ultimate strain increase wholly with the increase of strain rate, there is no obvious linear correlation between them. In addition, the micro test results show that the addition of an appropriate amount of carbon nanofibers help exert the small size effect, strengthen crack resistance and improve the microstructure of the matrix, effectively enhancing the dynamic compressive properties of concrete under impact load.
\end{abstract}

Keywords: Carbon nanofibers, Modified concrete, Impact load, Dynamic compressive properties, Strain rate effect

Correspondence: Wei Xia, xiaweiafeu@163.com

\section{Introduction}

With nearly two centuries of continuous development, concrete has become one of the most widely used structural materials in civil infrastructure and military protection engineering construction. With the rapid advance of modern materials science and technology, various modified concretes [1-5] have emerged, which promotes traditional concretes to achieve new breakthroughs in high strength, high performance, multi-function and intelligence. Carbon nanofibers (CNFs) are a kind of discontinuous nano-scale graphite fibers, which have excellent characteristics of both carbon fibers and nanomaterials. As they have large specific surface areas and strong interfacial bond, they are regarded as an ideal choice for property modification and reinforcement of composite materials $[6,7]$. Therefore, they have great potential for further optimizing and improving the overall performance of concrete if being evenly mixed into the concrete matrix.

In recent years, with the reduction of production cost and gradual expansion of production scale, the application prospect of carbon nanofibers in concrete has grown increasingly broad. Moreover, many representative achievements have been made in the domestic and foreign researches on carbon nanofibers reinforced concrete (CNFC). In the process of concrete preparation, Sanchez F et al. [8,9] added an appropriate amount of silica fume in order to improve the dispersion effect of carbon nanofibers, and then they found that carbon nanofibers had good dispersion state, which could refine the internal pores of concrete continuously. Gaodi [10] carried out a systematic study on the dispersion of carbon nanofibers in combination with the preparation 
characteristics of concrete, and he thought that the ideal dispersion effect of carbon nanofibers could be achieved by the combined action of surfactant surface treatment and ultrasound, which provides a useful reference for subsequent experimental researches. Zhuang Guofang [11] studied the pressure-sensitive characteristics of CNFC by conducting the tensile splitting strength and bending resistance tests, and the result showed that the electrical resistance of the samples increased with the increase of tensile stress and the decrease of compressive stress. Yao Bin [12] studied the impact of preparation conditions and external environment on the electrical properties of CNFC and found that the electrical resistivity of the samples increased gradually with the increase of age and ambient temperature. Maria S et al. [13] prepared the self-sensing concrete by adding carbon nanofibers and used it in actual structure for damage detection. His study result showed that, after the addition of carbon nanofibers, the resistivity of concrete significantly reduced while its electrical sensitivity improved. Meng W et al. [14] not only studied the impact of carbon nanofibers on the rheological properties, autogenous shrinkage, and pore structure of ultra-high performance concrete, but also proposed the uniform dispersion method of nanomaterials in ultra-high performance concrete. Zhang Xuan [15] carried out the laboratory test on carbon nanofibers modified hot mix asphalt concrete, and found that the indirect tensile strength and permanent deformation resistance of the modified concrete were improved to varying degrees compared with plain concrete. Wang Lilin et al. [16] tested the basic mechanical properties of concrete with different content of carbon nanofibers, and the test results showed that the compressive strength, bending strength and splitting tensile strength of concrete could be improved by adding an appropriate amount of carbon nanofibers. In sum, presently, scholars have mainly focused on the preparation methods, electrical properties, durability and static mechanical properties of CNFC, so the related research results on dynamic mechanical properties of CNFC have still been relatively rare. It is worth noting that, with the increasing complexity of architectural service environment, concrete structures are bound to face the tests of medium and high strain rate dynamic loads [17-19], such as earthquake, tsunami, strong wind and other natural disasters; in this context, even the explosion shock has set more stringent requirements on the bearing capacity and anti-impact compression performance of concrete materials. Therefore, in order to better guide the engineering practice, it is necessary to carry out the in-depth research on the dynamic compressive properties of CNFC.

In view of this, in this paper, based on the plain concrete with strength class "C45", four kinds of modified concrete samples with different carbon nanofiber volume fractions were prepared, and a 100-mm diameter Split Hopkinson Pressure Bar (SHPB) was used to carry out the impact compression test to obtain the dynamic stress-strain relationship of the samples at different strain rate levels. In addition, starting from the indicators such as dynamic compressive strength, dynamic compression deformation, impact toughness and dynamic elastic modulus, this study was conducted in combination with the SEM observation results and theoretical analysis to explore the law and action mechanism of the impact of carbon nanofibers content and strain rate levels on the dynamic compressive properties of modified concrete, providing theoretical support and scientific basis for practical application of CNFC in civil buildings and national defense projects.

\section{Materials and Methods}

\subsection{Raw Materials and Mix Proportion}

The 42.5R P.O cement, manufactured by Shaanxi Qinling Cement Group, has the fineness $(80 \mu \mathrm{m}$ sieve residue) of $7.6 \%$, the initial setting time and final setting time of which are 130 minutes and 310 minutes respectively; its coarse aggregates are limestone rubbles in two particle sizes: 5-10 mm accounting for 15\% and $10-20 \mathrm{~mm}$ accounting for $85 \%$, the bulk density of which is about $2,700 \mathrm{~kg} / \mathrm{m}^{3}$ and mud content of which is about $0.2 \%$; its fine aggregates are clean medium sand, the fineness modulus of which is 2.8 and the bulk density of which is about $2,630 \mathrm{~kg} / \mathrm{m}^{3}$; the water used for production is the ordinary tap water. The selected fiber materials were carbon nanofibers (Fig.1) manufactured by Beijing Deke Daojin Science and Technology Co., Ltd., the main 
performance indexes of which are shown in Table 1 . In addition, JKPCA-02 polycarboxylate high performance water reducer produced by Shaanxi Haoyu Concrete admixture Co., Ltd. and the tributyl phosphate defoamer produced by Shaanxi Lanxin Chemical Co., Ltd. were selected for tests. Table 2 shows the concrete mix proportion parameters of plain concrete with strength class " $\mathrm{C} 45$ " and CNFC, in which PC refers to the plain concrete without carbon nanofibers and CNFC01, CNFC02, CNFC03 and CNFC05 respectively refer to the modified concrete with different volume fractions of carbon nanofibers: $0.1 \%, 0.2 \%, 0.3 \%$ and $0.5 \%$ respectively.

Table 1 Main performance indexes of carbon nanofibers

\begin{tabular}{cccccccc}
\hline $\begin{array}{c}\text { Purity } \\
(\%)\end{array}$ & $\begin{array}{c}\text { Filament } \\
\text { diameter } \\
(\mathrm{nm})\end{array}$ & $\begin{array}{c}\text { Length- } \\
\text { diamete } \\
\mathrm{r} \text { ratio }\end{array}$ & $\begin{array}{c}\text { Thermal } \\
\text { conductivity } \\
\text { coefficient } \\
\left(\mathrm{W} \cdot\left(\mathrm{m} \cdot{ }^{\circ} \mathrm{C}\right)^{-1}\right)\end{array}$ & $\begin{array}{c}\text { Electrical } \\
\text { resistivity } \\
(\Omega \cdot \mathrm{cm})\end{array}$ & $\begin{array}{c}\text { Thermal } \\
\text { expansion } \\
\text { coefficient } \\
\left({ }^{\circ} \mathrm{C}^{-1}\right)\end{array}$ & $\begin{array}{c}\text { Specific } \\
\text { surface } \\
\text { area } \\
\left(\mathrm{m}^{2} \cdot \mathrm{g}^{-1}\right)\end{array}$ & $\begin{array}{c}\text { Density } \\
\left(\mathrm{g} \cdot \mathrm{cm}^{-3}\right)\end{array}$ \\
\hline 99.9 & $100 \sim 200$ & 70 & 2,000 & $<0.012$ & 1 & 300 & 0.18 \\
\hline
\end{tabular}

Table 2 Mix proportion of concrete $\left(\mathrm{kg} / \mathrm{m}^{3}\right)$

\begin{tabular}{cccccccc}
\hline Sample No. & Cement & Rubble & Sand & Water & Defoamer & $\begin{array}{c}\text { Water } \\
\text { reducer }\end{array}$ & $\begin{array}{c}\text { Carbon } \\
\text { nanofibers }\end{array}$ \\
\hline PC & 495 & 1,008 & 672 & 180 & 0 & 0 & 0 \\
CNFC01 & 495 & 1,008 & 672 & 180 & 0.30 & 5.0 & 0.18 \\
CNFC02 & 495 & 1,008 & 672 & 180 & 0.45 & 7.5 & 0.36 \\
CNFC03 & 495 & 1,008 & 672 & 180 & 0.60 & 10.0 & 0.54 \\
CNFC05 & 495 & 1,008 & 672 & 180 & 0.90 & 15.0 & 0.90 \\
\hline
\end{tabular}

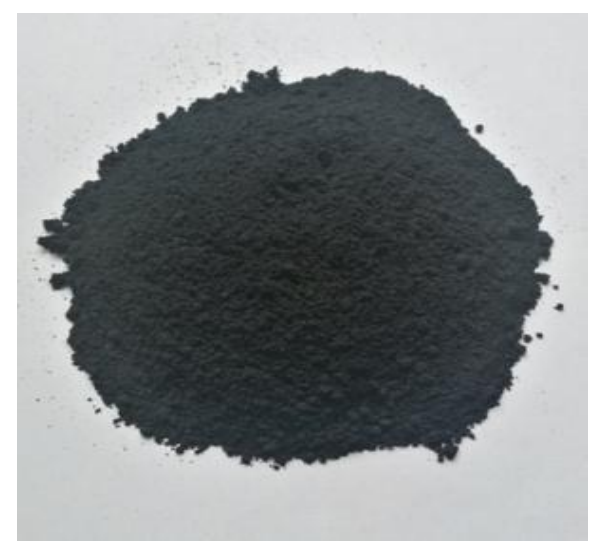

Fig.1 Carbon nanofibers

\subsection{Sample Preparation}

Based on the existing literature [10], the chemical dispersion method (specifically, adding carbon nanofibers to the dispersant solution in which water reducer served as dispersant) was used to improve the agglomerates winding phenomenon of carbon nanofibers. The pouring of concrete samples was based on the "method of sand and rubbles enveloped with cement". For samples in the CNFC group, their pouring process is shown in Fig.2. The pouring of concrete mixture was first completed, and then it was left in the room to stand for 24 hours. After the formworks were removed, the formed samples were quickly moved into the standard curing chamber (with the temperature of $(20 \pm 2){ }^{\circ} \mathrm{C}$ and the relative humidity of $\left.\mathrm{RH}>95 \%\right)$ for curing for 28 days. The samples in two sizes were prepared: the cube samples $(100 \mathrm{~mm} \times 100 \mathrm{~mm} \times 100 \mathrm{~mm})$ for the test on static compressive strength of concrete and short cylinder samples for dynamic test of concrete. Since the dynamic compression test was carried out by using a 100-mm diameter SHPB test system, the size of the samples was designed as a short cylinder with the diameter of $100 \mathrm{~mm}$ and the height of $50 \mathrm{~mm}$ (Fig.3). Finally, after the completion of sample curing, the 
double-face grinding machine SHM-200 was used for polishing and processing two round end-faces to ensure that the surface roughness was less than $0.02 \mathrm{~mm}[20]$.

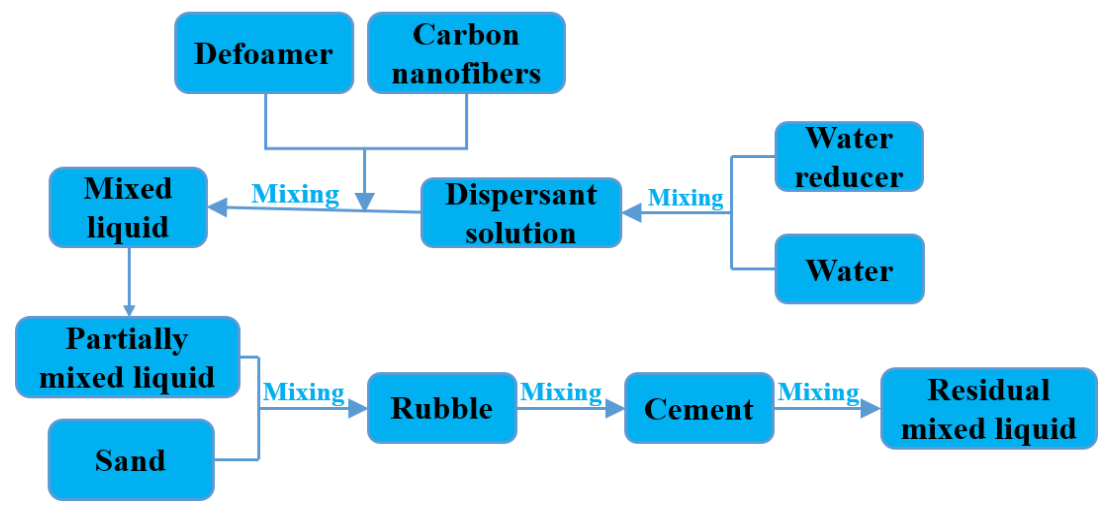

Fig.2 Mechanism for pouring of CNFC group samples

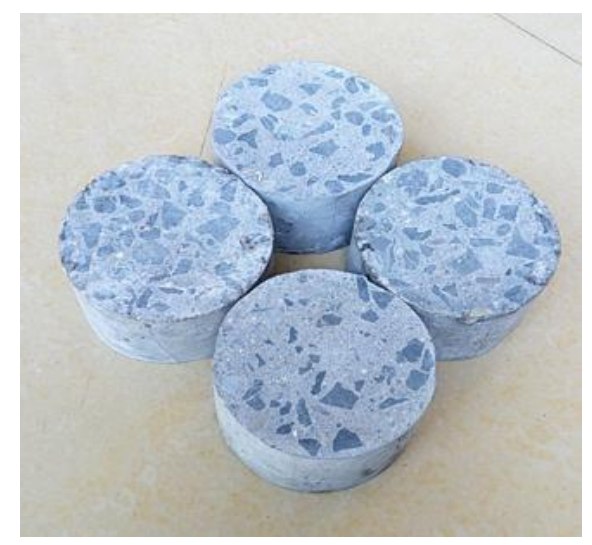

Fig.3 Processed short cylinder samples

\subsection{Test Method}

The static test process is described as follows: According to the relevant provisions in the Standard for Test Method of Mechanical Properties on Concrete (GB/T 50081-2019), the static compression test was conducted by using electro-hydraulic servo compression testing machine (Fig.4). When the samples were close to failure, the throttle adjustment was stopped and their load displacement curves were recorded. On this basis, by multiplying the test result by the conversion coefficient of 0.95 , the average static compressive strength values of concrete samples were obtained, which are shown in Table 3 (The results are used only for test contrast, not for other purposes).

Table 3 Average static compressive strength of samples

\begin{tabular}{cccccc}
\hline Test groups & PC & CNFC01 & CNFC02 & CNFC03 & CNFC05 \\
\hline $\begin{array}{c}\text { Compressive } \\
\text { strength/MPa }\end{array}$ & 46.12 & 47.26 & 48.93 & 50.34 & 45.68 \\
\hline
\end{tabular}

The dynamic test is described as follows: First of all, a 100mm-diameter SHPB test system and the propagation process of stress wave in test are shown in Fig.5 and Fig.6 respectively. The compressed gas from the air compressor enabled the bullet to have a certain initial velocity to produce incident stress wave $\varepsilon_{I}(t)$ after impacting the incident bar. When $\varepsilon_{I}(t)$ passed through the interface $A_{1}$, one part of it was reflected to form the reflected wave $\varepsilon_{R}(t)$; but the other part of it was transmitted into the transmission bar through the sample to form 
transmission wave $\varepsilon_{T}(t)$, and then the transmission bar impacted the absorption bar and the absorption bar subsequently impacted the energy absorption device to exhaust the impact energy. A 1 mm-thick H62 round brass sheet was used to reshape the initial stress wave, which was based on the existing research results [21, 22]. Meanwhile, a layer of mixture of graphite and lubricating oil was evenly applied on the contact interface between the sample and bars to reduce the impact of friction effect. Actually, there were five strain rate levels set in this test. The strain rate is the reflection of impact velocity, and these two are approximately linearly dependent basically [23]. The impact velocity is determined jointly by the applied air pressure and its action distance. Therefore, in the test, the impact velocity was controlled usually by virtue of changing the magnitude of input air pressure while remaining the air pressure action distance unchanged, as is shown in Fig.7. In addition, it should be noted that the impact velocity of the bullet is also affected by the test environment. So, although the input air pressure and its action distance can remain unchanged, the impact velocity may not be completely identical, that is, the strain rate may be slightly different under the same controllable shooting conditions. In view of the dispersion of concrete in test, at least three samples were tested when the air pressure was input each time. Finally, the test data was processed by using the "three-wave method" [24]. The SHPB test results of samples in each group are shown in Table 4.

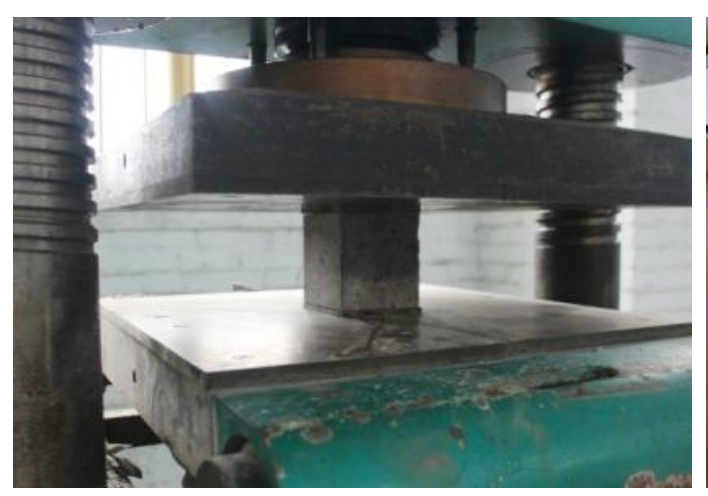

Fig.4 Static compression test

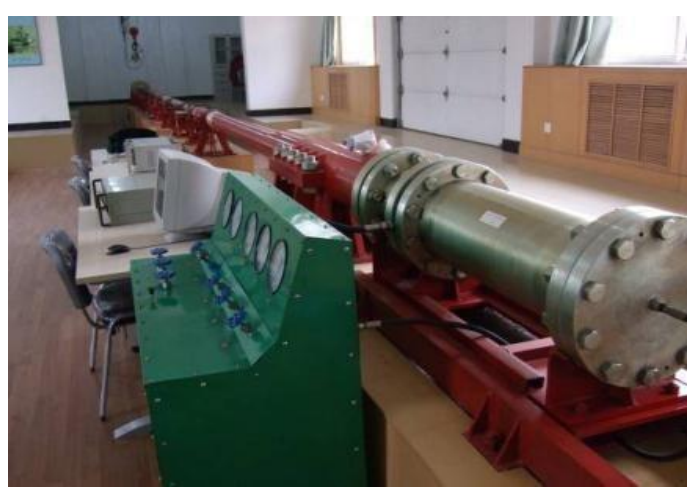

Fig.5 A 100mm-diameter SHPB test system

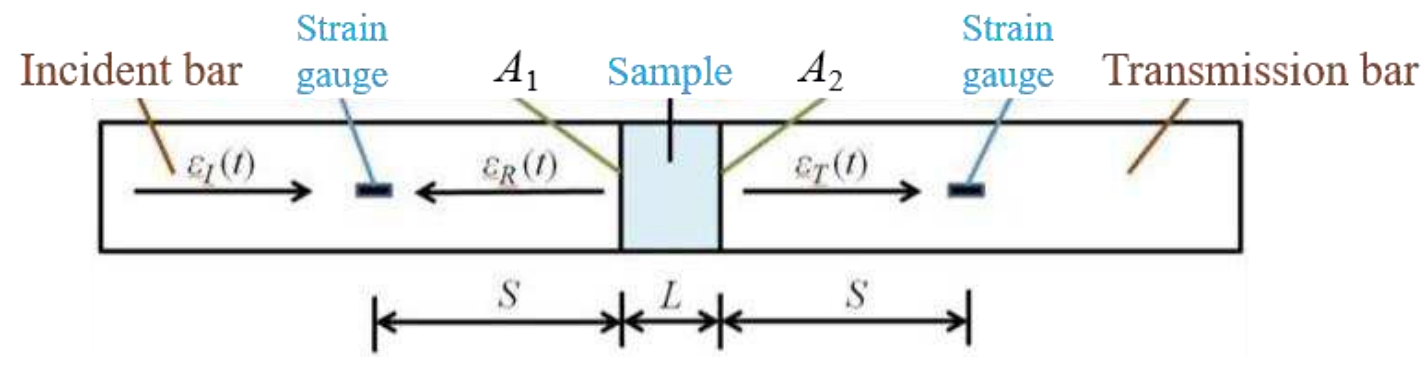

Fig.6 Stress wave propagation at interfaces

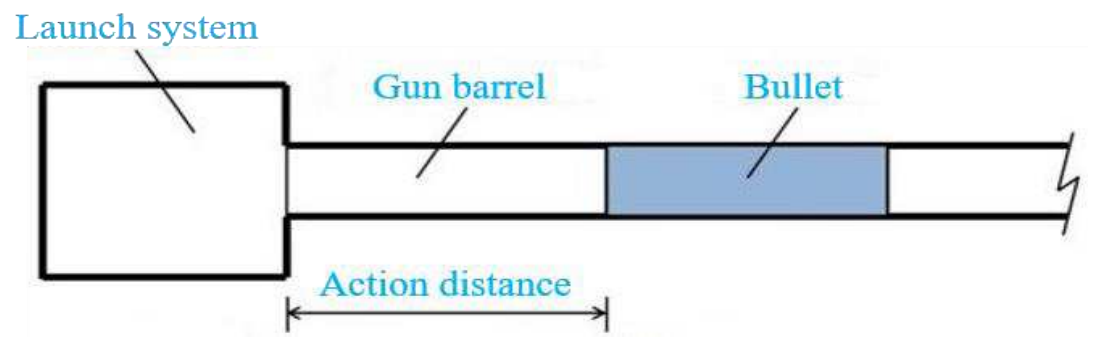

Fig.7 Control of bullet impact speed

Table 4 Summary of SHPB tests on concrete 


\begin{tabular}{|c|c|c|c|c|c|c|c|c|}
\hline Group & $\mathrm{SN}$ & $\begin{array}{l}\text { Average } \\
\text { strain rate } \\
\overline{\dot{\varepsilon}}\left(\mathrm{s}^{-1}\right)\end{array}$ & $\begin{array}{c}\text { Dynamic } \\
\text { compressive } \\
\text { strength } \\
f_{c, d}(\mathrm{Mpa})\end{array}$ & $\begin{array}{c}\text { Peak strain } \\
\varepsilon_{p}\left(\times 10^{-3}\right)\end{array}$ & $\begin{array}{l}\text { Ultimate } \\
\text { strain } \\
\varepsilon_{u}\left(\times 10^{-3}\right)\end{array}$ & $\begin{array}{l}\text { Impact } \\
\text { toughness } \\
I T\left(\mathrm{KJ} / \mathrm{m}^{3}\right)\end{array}$ & $\begin{array}{c}\text { Dynamic } \\
\text { modulus of } \\
\text { elasticity } \\
E_{c}^{d}(\mathrm{GPa})\end{array}$ & $\begin{array}{c}\text { Dynamic } \\
\text { growth factor } \\
I_{c}^{d}\end{array}$ \\
\hline \multirow{5}{*}{$\mathrm{PC}$} & 1 & 51.46 & 48.61 & 7.87 & 21.08 & 568.4 & 9.35 & 1.05 \\
\hline & 2 & 61.31 & 54.85 & 8.12 & 21.78 & 609.99 & 10.03 & 1.19 \\
\hline & 3 & 76.49 & 60.54 & 8.43 & 24.22 & 721.94 & 11.13 & 1.31 \\
\hline & 4 & 90.83 & 71.02 & 8.72 & 24.67 & 932.87 & 11.59 & 1.54 \\
\hline & 5 & 109.28 & 78.53 & 9.42 & 28.23 & 1134.4 & 12.83 & 1.7 \\
\hline \multirow{5}{*}{ CNFC01 } & 1 & 62.48 & 56.77 & 7.71 & 21.56 & 674.51 & 9.33 & 1.2 \\
\hline & 2 & 74.06 & 59.99 & 8.80 & 23.39 & 718.72 & 9.91 & 1.27 \\
\hline & 3 & 83.94 & 66.72 & 9.35 & 26.05 & 836.28 & 10.18 & 1.41 \\
\hline & 4 & 92.17 & 72.51 & 9.63 & 27.91 & 1039.16 & 10.84 & 1.53 \\
\hline & 5 & 108.93 & 80.9 & 10.59 & 29.12 & 1215.31 & 11.12 & 1.71 \\
\hline \multirow{5}{*}{$\mathrm{CNFCO} 2$} & 1 & 57.81 & 54.45 & 7.22 & 21.90 & 618.67 & 9.95 & 1.11 \\
\hline & 2 & 76.38 & 62.68 & 8.42 & 23.16 & 755.9 & 12.1 & 1.28 \\
\hline & 3 & 86.92 & 70.46 & 8.67 & 25.05 & 1013.23 & 12.39 & 1.44 \\
\hline & 4 & 91.85 & 73.28 & 9.02 & 28.88 & 1186.4 & 12.86 & 1.5 \\
\hline & 5 & 108.06 & 81.24 & 9.66 & 30.90 & 1443.45 & 13.78 & 1.66 \\
\hline \multirow{5}{*}{$\mathrm{CNFC03}$} & 1 & 58.79 & 56.67 & 8.84 & 21.48 & 744.03 & 8.94 & 1.13 \\
\hline & 2 & 80.47 & 67.58 & 9.26 & 24.55 & 933.02 & 9.93 & 1.34 \\
\hline & 3 & 92.16 & 74.94 & 9.91 & 26.01 & 1017.42 & 10.64 & 1.49 \\
\hline & 4 & 104.58 & 79.42 & 10.36 & 29.24 & 1263.2 & 10.89 & 1.58 \\
\hline & 5 & 111.23 & 84.43 & 11.28 & 32.34 & 1504.44 & 11.21 & 1.68 \\
\hline \multirow{5}{*}{ CNFC05 } & 1 & 50.89 & 50.56 & 8.27 & 22.94 & 669.64 & 8.35 & 1.11 \\
\hline & 2 & 60.77 & 57.79 & 8.84 & 25.27 & 868.77 & 8.98 & 1.27 \\
\hline & 3 & 78.39 & 62.33 & 9.42 & 26.69 & 898.32 & 9.38 & 1.36 \\
\hline & 4 & 89.04 & 69.3 & 11.25 & 28.12 & 1140.47 & 10.12 & 1.52 \\
\hline & 5 & 97.65 & 73.03 & 11.59 & 31.86 & 1272.81 & 10.38 & 1.6 \\
\hline
\end{tabular}

\section{Results and Analysis}

\subsection{Dynamic Stress-Strain Curve}

The stress-strain curve comprehensively reflects the mechanical behavior change of concrete when subjected to external load. Besides, the dynamic stress-strain curves of plain concrete samples and CNFC samples under different strain rate levels, which are obtained by calculation based on the "three-wave method", are shown in Fig. 8 and Fig.9 respectively. After the careful analysis, the following results are shown: (1) Generally speaking, the geometric shapes of the ascending sections before the peaks of stress-strain curves for samples in different groups are basically the same, which can be roughly divided into three stages: compaction, linear elastic deformation and yield failure. Under the impact load, original pores and other defects inside the matrix of sample are first compressed and compacted, which leads to the slow increase of the strength of the sample; after that, the sample enters the stage of linear elastic deformation, where there is the approximately linear correlation roughly between the stress growth and deformation. When the sample is compressed to the yield point, its damage degree intensifies and the stress growth slows down again; when the load reaches the peak point, the sample is damaged and its residual strength decreases gradually. (2) For the stress-strain curve, its intuitive expression is the fluctuation of the tangent slope of the curve: first it ascends gradually in the compaction stage, and then remains unchanged basically in the linear elastic stage, and finally descends gradually in the yield failure stage. (3) The strain range in the descending section of the curve is generally larger than that in the ascending section, indicating that the samples still have good deformation capacity after being damaged due to a certain residual strength. (4) The dynamic stress-strain curve for the samples in the PC group and CNFC group is significantly affected by the strain rate; 
specifically, the higher the strain rate is, the higher the peak stress of sample is and the greater its compression deformation is. (5) The addition of carbon nanofibers enables the "platform area" near the peak point of stress-strain curve of concrete sample to become broad, indicating that carbon nanofibers can improve the deformation and failure mechanism of concrete and enhance the ductility of concrete to a certain extent; moreover, their enhancement degree is closely related to the content of carbon nanofibers.

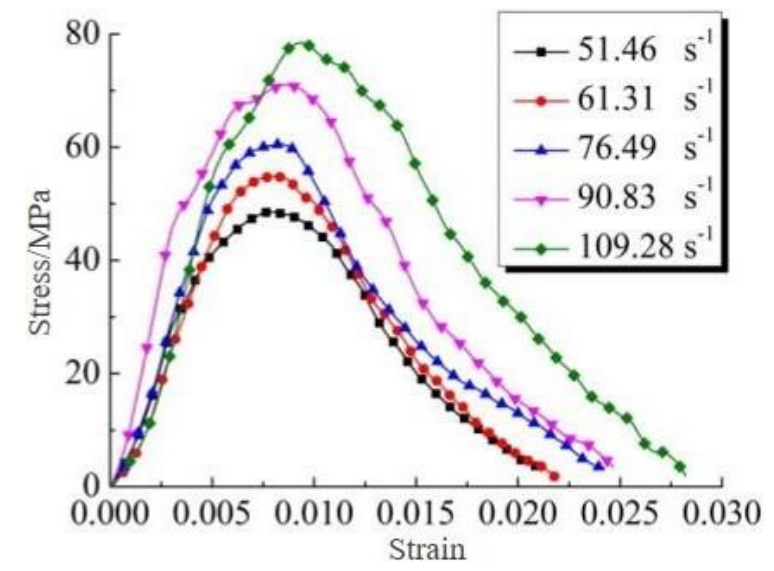

Fig. 8 Stress-Strain curve of plain concrete under different strain rates
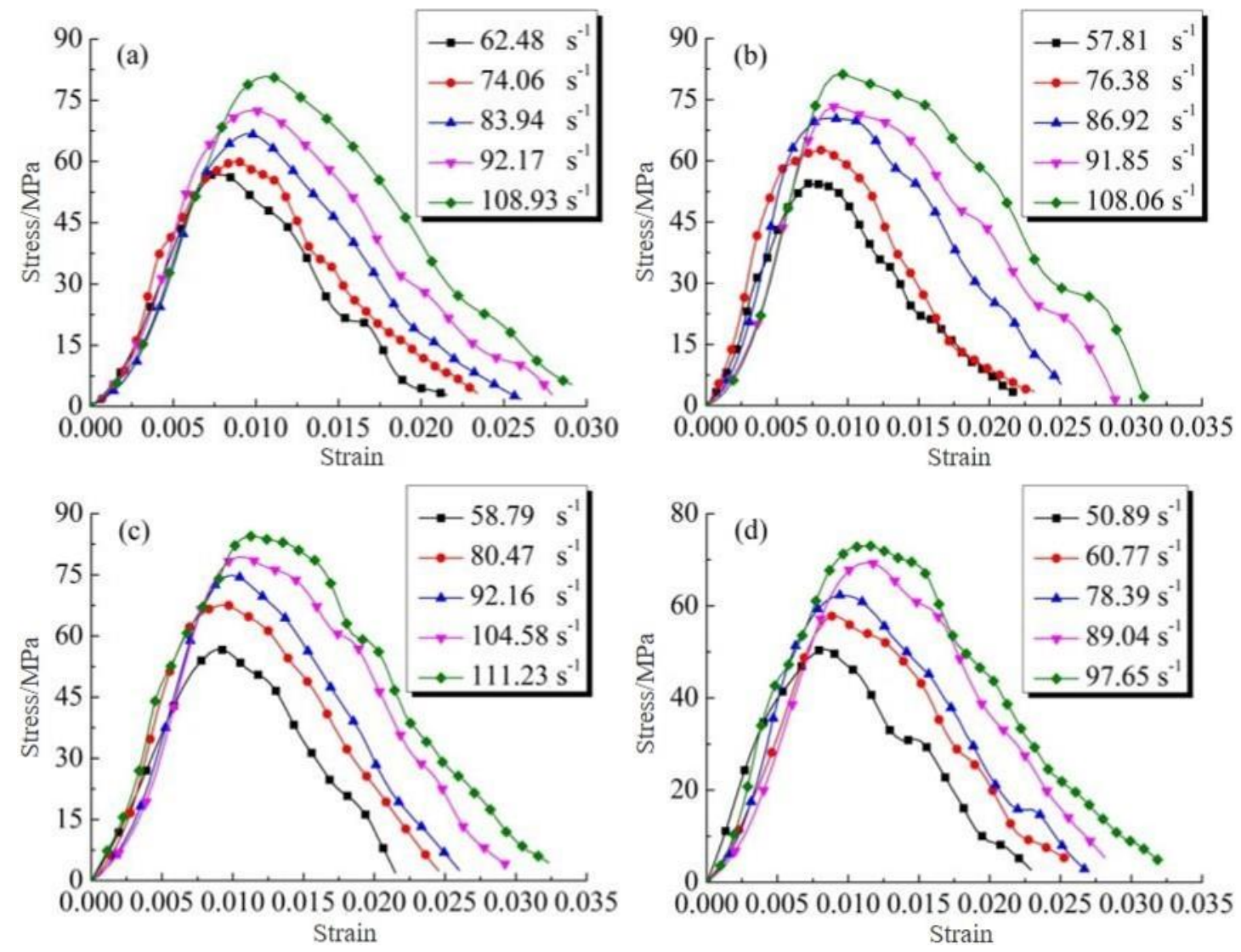

Fig.9 Stress-Strain curves of carbon nanofibers reinforced concrete under different strain rates

(a)CNFC01, (b)CNFC02, (c)CNFC03, (d)CNFC05

\subsection{Dynamic Compressive Strength}

The dynamic compressive strength of the sample is the corresponding stress at the peak point of the stress-strain curve, which can reflect the strength characteristics of concrete under impact load. Fig.10 shows the 
change rule of dynamic compressive strength of concrete samples under different strain rate levels. After the analysis, these results are shown: (1) With the increase of strain rate level, the dynamic compressive strength of samples in PC group and CNFC group increases significantly, indicating that the strain rate has extremely obvious enhancement effect. (2) According to the change relationship between the dynamic compressive strength and the strain rate, it can be seen that there is the approximately linear relationship of increase between them; moreover, after the linear fitting between them, it can be seen from Formula (2) that the fitting effect of the two is better. (3) On the whole, compared with plain concrete, the addition of an appropriate amount of carbon nanofibers can enhance the dynamic compressive strength of concrete. At the same strain rate level, when the fiber content is $0.3 \%$, its enhancement effect is the best; but when the fiber content is $0.5 \%$, its enhancement effect is weaker.

The dynamic intensity growth factor is defined as follows:

$$
I_{c}^{d}=f_{c, d} / f_{c, s}
$$

In the formula, $f_{c, s}$ and $f_{c, d}$ represent the compressive strength of concrete under static and dynamic loads respectively.

The dynamic strength growth factor represents the increase range of compressive strength of the samples under impact load relative to that under static load, which reflects the enhancement effect of dynamic load on concrete strength. Fig.11 shows the relationship between the dynamic strength growth factors of samples in various groups and the strain rates specifically, there is an approximately linear relationship between these two. After the linear fitting between them, the result can be seen in Formula (3). The analysis result shows that the dynamic strength growth factor also has relatively obvious strain rate enhancement effect, but the impact of carbon nanofibers content on dynamic strength growth factor of concrete at the same strain rate level hasn't shown obvious law, and even when the fiber content is $0.3 \%$, its enhancement effect is not as good as that of PC group.

\begin{tabular}{|c|c|}
\hline$f_{c, d}=22.0878+0.5216 \overline{\dot{\varepsilon}}$ & $\left(R^{2}=0.9874\right)$ \\
\hline CNFC01: $\quad f_{c, d}=21.4446+0.5448 \overline{\dot{\varepsilon}}$ & $\left(R^{2}=0.9793\right)$ \\
\hline CNFC02: $\quad f_{c, d}=22.3441+0.5472 \overline{\dot{\varepsilon}}$ & $\left(R^{2}=0.9899\right)$ \\
\hline CNFC03: $\quad f_{c, d}=26.0754+0.5202 \overline{\dot{\varepsilon}}$ & $\left(R^{2}=0.9934\right)$ \\
\hline CNFC05: $\quad f_{c, d}=28.1470+0.4573 \overline{\dot{\varepsilon}}$ & $\left(R^{2}=0.9702\right)$ \\
\hline$I_{c}^{d}=0.4767+0.0113 \overline{\dot{\varepsilon}}$ & $\left(R^{2}=0.9858\right)$ \\
\hline CNFC01: $\quad I_{c}^{d}=0.4559+0.0115 \overline{\dot{\varepsilon}}$ & $\left(R^{2}=0.9810\right)$ \\
\hline $\mathrm{CNFC02}: \quad I_{c}^{d}=0.4507+0.0113 \overline{\dot{\varepsilon}}$ & $\left(R^{2}=0.9895\right)$ \\
\hline CNFC03: $\quad I_{c}^{d}=0.5201+0.0103 \overline{\dot{\varepsilon}}$ & $\left(R^{2}=0.9929\right)$ \\
\hline CNFC05: $\quad I_{c}^{d}=0.6225+0.0099 \overline{\dot{\varepsilon}}$ & $\left(R^{2}=0.9637\right)$ \\
\hline
\end{tabular}

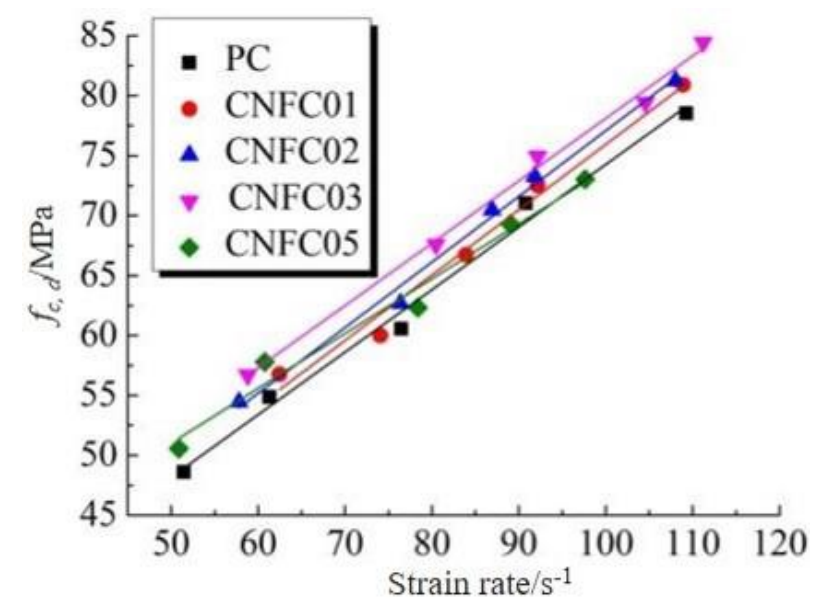


Fig.10 Dynamic compressive strength of concrete under different strain rates

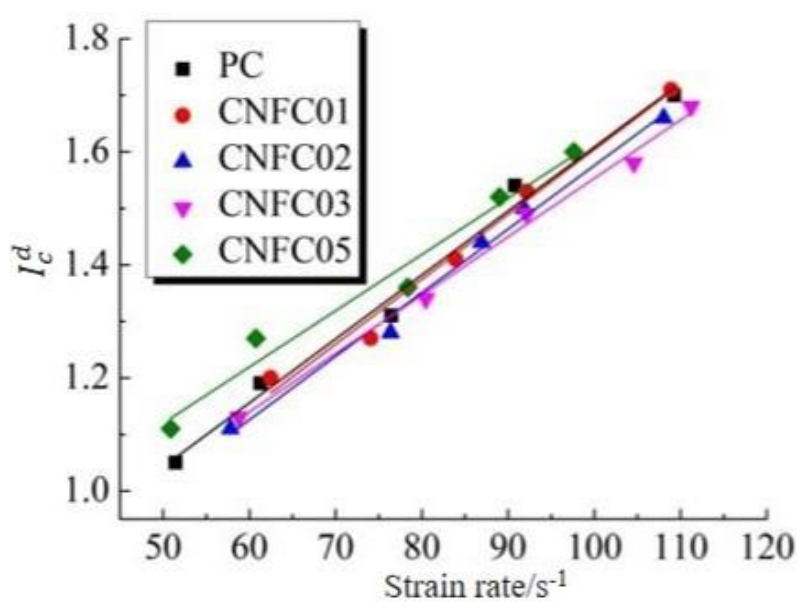

Fig.11 Dynamic strength growth factor of concrete under different strain rates

\subsection{Dynamic Compression Deformation}

Dynamic compression deformation is an important reference index to analyze the mechanical characteristics of concrete under impact load. In this paper, the dynamic compression deformation characteristics of concrete samples are studied through the peak strain and ultimate strain.

The peak strain of concrete sample is the corresponding strain at the peak point of dynamic stress-strain curve. Generally speaking, when the load reaches its peak, the sample enters the failure stage, so the peak strain can effectively represent the failure deformation characteristics of the sample. Fig.12 shows the relationship between the dynamic peak strain of samples in various groups and the strain rates. After the analysis, these results are shown: (1) In general, with the increase of strain rate level, the dynamic peak strain of concrete shows an increasing trend, but it is different from the strength characteristics as the linear correlation between dynamic peak strain and strain rate is not significant. (2) The addition of an appropriate amount of carbon nanofibers helps improve the deformation performance of concrete and enhance the dynamic peak strain. When the content of nanofibers is $0.5 \%$, its enhancement effect is the best, but it fails to show the change rule of "the enhancement effect intensifies with the increase of the fiber content", which may be due to the uneven dispersion of carbon nanofibers in concrete mixing caused by individual fiber volume fraction.

The ultimate strain of concrete sample is the strain generated after the load of sample is completely destroyed, which is expressed by the final strain value of dynamic stress-strain curve. Fig.13 shows the relationship between the dynamic ultimate strain of samples in various group and the strain rates. Obviously, with the increase of strain rate level, the dynamic ultimate strain of samples in various groups gradually increases, but there is no obvious change relationship shown between the dynamic ultimate strain and fiber content. However, it can be found that, when the fiber content is $0.5 \%$, it has the best enhancement effect on dynamic ultimate strain. 


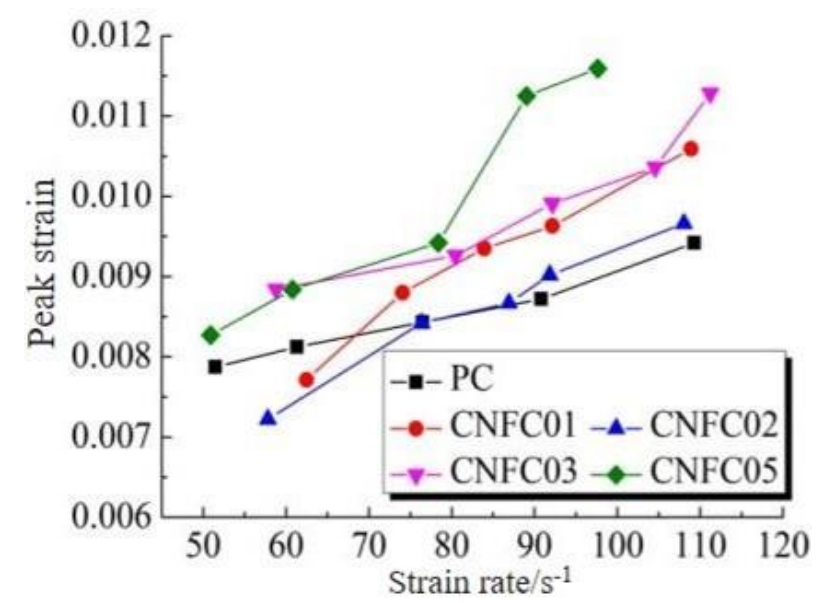

Fig.12 Dynamic peak strain of concrete under different strain rates

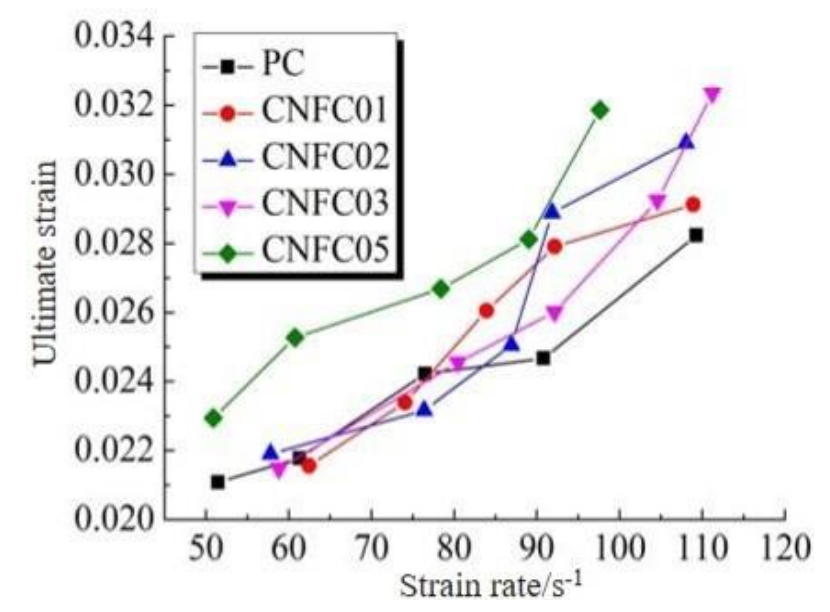

Fig.13 Dynamic ultimate strain of concrete under different strain rates

\subsection{Impact Toughness}

Energy change is bound to follow concrete failure under loads. Especially under impact loads, the transformation and dissipation of energy is extraordinarily fast and active. Impact toughness (IT) was used in this paper to characterize the energy absorbed from the stress-strain development process to specimen failure under impact loads. The physical meaning of impact toughness is the area surrounded by the stress-strain curve and the coordinate axes and can be expressed as [25]:

$$
I T=\int_{0}^{\varepsilon_{u}} f d \varepsilon
$$

where $f$ is the dynamic stress-strain curve of the specimen, and $\varepsilon_{u}$ is the dynamic ultimate strain of the curve.

The relation between the change of the impact toughness and the strain rate of each specimen is shown in Fig.14. The following can be known through analysis: (1) The impact toughness was extremely sensitive to the strain rate and increased with the strain rate. (2) Adding carbon nanofibers can improve the impact toughness of concrete to some extent. Generally, the impact toughness increased to a certain degree with the increase of fiber incorporation under the same strain rate. (3) Under a low strain rate, the improvement of impact toughness was greater with a fiber volume fraction of $0.2 \%$ than $0.3 \%$. The opposite was true under a high strain rate. (4) Through observation of the relation between the change of the impact toughness and the strain rate, it can be seen that the two has a near-linear correlation. Formula (5) is the fitting result of the two, which is good. 


$\left\{\begin{array}{ccc}\text { PC }: & I T=3.2639+10.1479 \overline{\dot{\varepsilon}} & \left(R^{2}=0.9648\right) \\ \text { CNFC01: } & I T=-271.9173+13.7023 \overline{\dot{\varepsilon}} & \left(R^{2}=0.9709\right) \\ \text { CNFC02: } & I T=-448.3160+17.2420 \overline{\dot{\varepsilon}} & \left(R^{2}=0.9315\right) \\ \text { CNFC03: } & I T=-205.5699+14.4042 \overline{\dot{\varepsilon}} & \left(R^{2}=0.9055\right) \\ \text { CNFC05: } \quad I T=10.9772+12.2302 \overline{\dot{\varepsilon}} & \left(R^{2}=0.9303\right)\end{array}\right.$

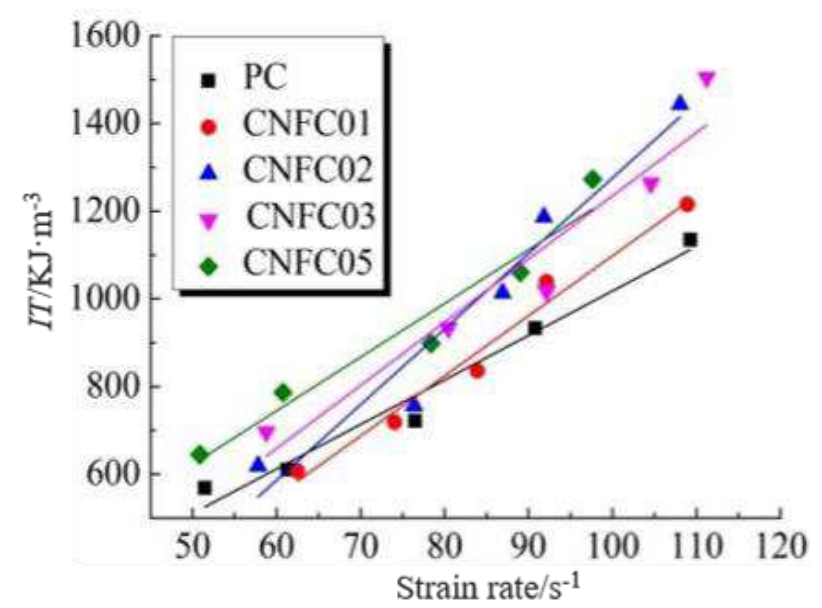

Fig.14 Impact toughness of concrete under different strain rates

\subsection{Dynamic Modulus of Elasticity}

Modulus of elasticity is a common index indicating the difficulty level of material deformation. Its general definition is the ratio of stress to the corresponding strain of an ideal material undergoing minor deformation. The slopes of the stress-strain curve of the concrete specimen during the linear elastic deformation were used as the dynamic modulus of elasticity in this paper. The relation between the dynamic modulus of elasticity and the strain rate of each specimen is shown in Fig.15. The following can be known through analysis: (1) The dynamic modulus of elasticity of the concrete increased with the strain rate, and there was a near-linear growth relation between the two. Linear fitting was performed for them, as shown in Formula (6). (2) Different volume fractions of carbon nanofibers for the concrete had different effects on the dynamic modulus of elasticity of the concrete. The dynamic modulus of elasticity was only improved with the volume fraction of $0.2 \%$ to some extent and was reduced with other volume fractions. Besides, the greater the volume fraction, the more the dynamic modulus of elasticity was reduced. The dynamic modulus of elasticity was decided by both the dynamic compressive strength and the corresponding deformation amount, which was responsible for the result of this experiment. Although the addition of carbon nanofibers improved both the dynamic compressive strength and the dynamic compression deformation to some extent, the improvement of the deformation was greater than that of the strength for most volume fractions $(0.1 \%, 0.3 \%$ and $0.5 \%)$, leading to the decrease of the value of the dynamic modulus of elasticity

$\left\{\begin{array}{cll}\mathrm{PC}: & E_{e}^{d}=6.4271+0.0585 \dot{\dot{\varepsilon}} & \left(R^{2}=0.9850\right) \\ \mathrm{CNFC} 01: & E_{e}^{d}=6.9261+0.0397 \overline{\dot{\varepsilon}} & \left(R^{2}=0.9382\right) \\ \mathrm{CNFC} 02: & E_{e}^{d}=5.9634+0.0743 \overline{\dot{\varepsilon}} & \left(R^{2}=0.9404\right) \\ \mathrm{CNFC03:} & E_{e}^{d}=6.4633+0.0431 \overline{\dot{\varepsilon}} & \left(R^{2}=0.9781\right) \\ \mathrm{CNFC} 05: & E_{e}^{d}=6.2646+0.0422 \overline{\dot{\varepsilon}} & \left(R^{2}=0.9644\right)\end{array}\right.$




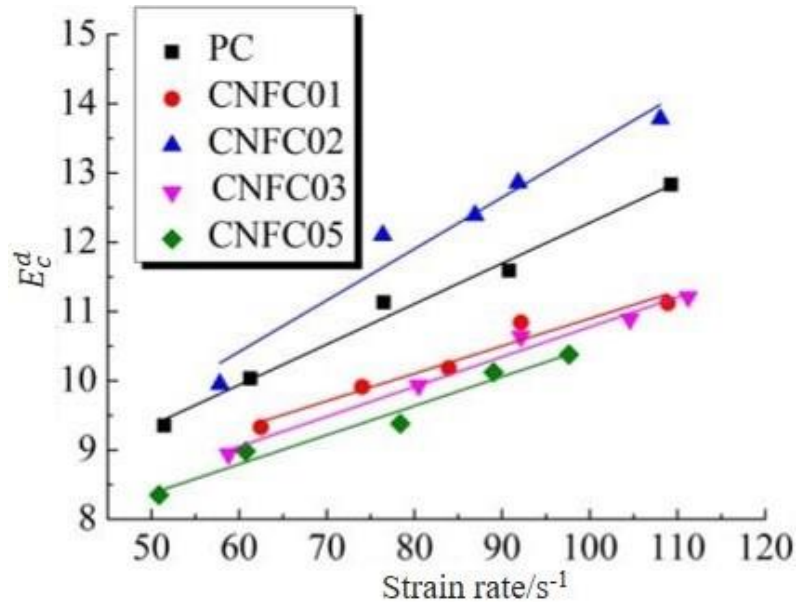

Fig.15 Dynamic modulus of elasticity of concrete under different strain rates

\section{Mechanism Analysis}

CNFC is a new type of fiber-reinforced concrete prepared by adding a certain amount of disorderly distributed carbon nanofibers into plain concrete. As CNFC is a multi-phase heterogeneous composite, the physical and mechanical properties of coarse and fine aggregates, cement hydration products, admixtures and reinforcing components inside the CNFC matrix differ. Besides, concrete is a brittle material with significant strain rate sensitivity and viscosity. Under external impact loads, the dynamic compressive mechanical properties of CNFC complicate as a result of the viscous effect and micro inertial effect of pore water [26].

\subsection{Macroscopic Failure Modes of Concrete}

Macroscopic failure modes directly reflect concrete failure under loads. As can be seen through analysis of typical failure mode of each specimen in Fig.16 and Fig.17, the degree of specimen failure gradually aggravated with the increase of the strain rate. Although the specimen failure modes were different under different strain rates, they can be basically divided into four categories: (1) Edge failure. Most parts of the specimen remained complete. Although there were cracks, only minor failure occurred at the edges and usually at low strain rates. For example, the failure mode of the CNFC01 specimen under the strain rate of $62.48 \mathrm{~s}^{-1}$. (2) Core failure. The specimen damage was more severe than that in the case of edge failure. The specimen damage was mostly peripheral damage and relatively severe, while the central part remained relatively complete. For example, the failure mode of the CNFC01 specimen under the strain rate of $74.06 \mathrm{~s}^{-1}$. (3) Fragmentation failure. Such failure was more severe than core failure. The specimen broke into relatively big blocks under loads. For example, the failure modes of the CNFC02 and CNFC03 specimens under the strain rate of $73.68 \mathrm{~s}^{-1}$ and $80.47 \mathrm{~s}^{-1}$ respectively. (4) Crushing failure. The specimen with such failure mode was basically broken into pieces and almost without any blocks. Such failure usually occurred under a high strain rate. Through comparative analysis, it can be seen that the failure mode of the plain concrete specimen was core failure under a low strain rate and crushing failure under the other strain rates, indicating that its dynamic mechanical properties were poor, while the failure modes of the CNFC specimens going through carbon nanofibers modification were greatly improved, with their failure modes being mainly core failure or fragmentation failure, which indicated that adding carbon nanofibers enhanced the dynamic mechanical properties of the concrete significantly. 


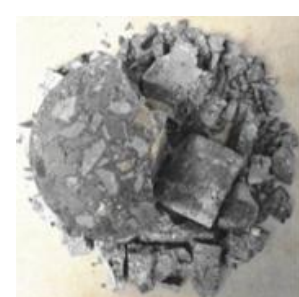

$51.46 \mathrm{~s}^{-1}$

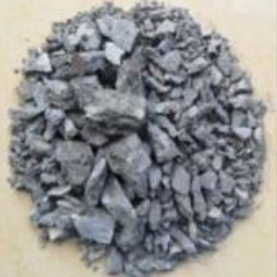

$61.31 \mathrm{~s}^{-1}$

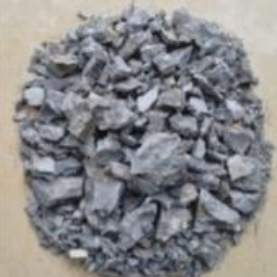

$76.49 \mathrm{~s}^{-1}$

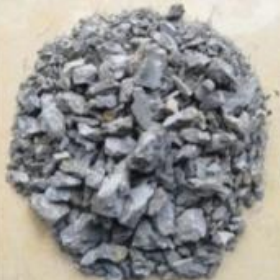

$90.83 \mathrm{~s}^{-1}$

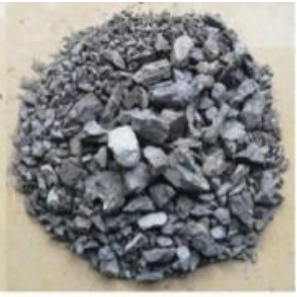

$109.28 \mathrm{~s}^{-1}$

Fig.16 Typical failure mode of plain concrete under different strain rates

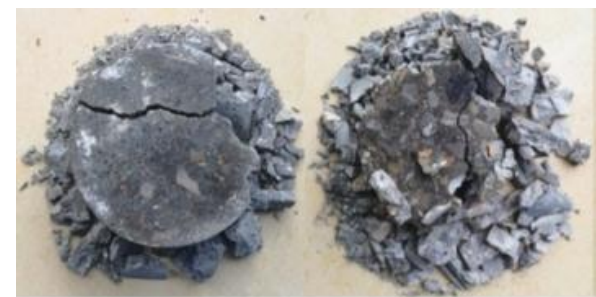

$62.48 \mathrm{~s}^{-1}$

$74.06 \mathrm{~s}^{-1}$

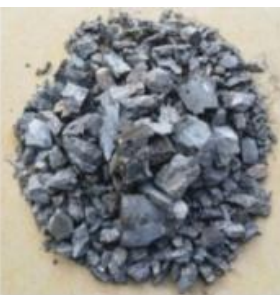

$83.94 \mathrm{~s}^{-1}$

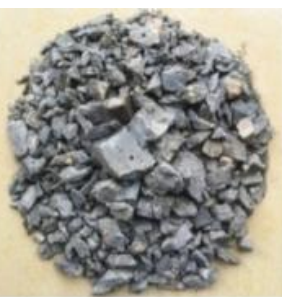

$92.17 \mathrm{~s}^{-1}$

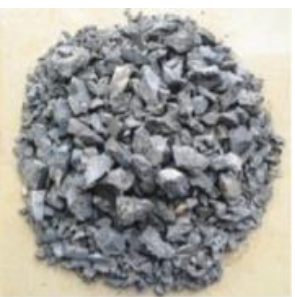

$108.93 \mathrm{~s}^{-1}$

(a)

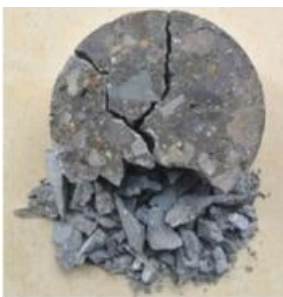

$57.81 \mathrm{~s}^{-1}$

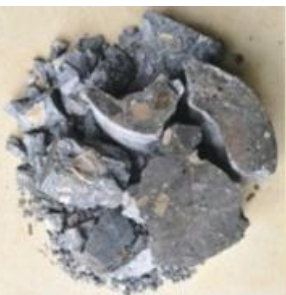

$76.38 \mathrm{~s}^{-1}$

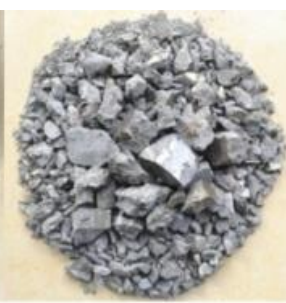

$86.92 \mathrm{~s}^{-1}$

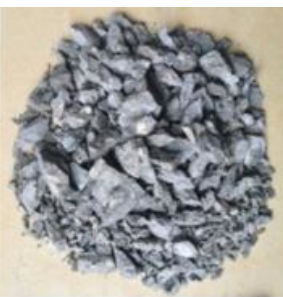

$91.85 \mathrm{~s}^{-1}$

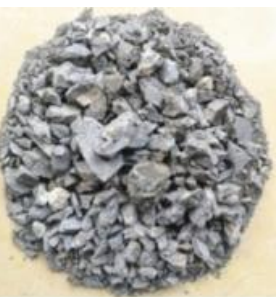

$108.06 \mathrm{~s}^{-1}$

(b)

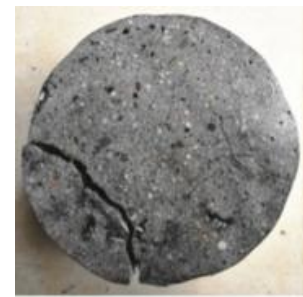

$58.79 \mathrm{~s}^{-1}$

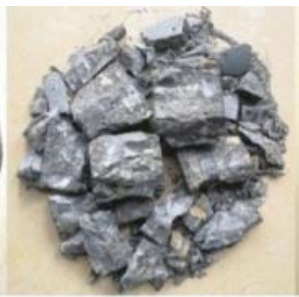

$80.47 \mathrm{~s}^{-1}$

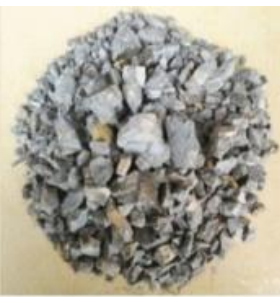

$92.16 \mathrm{~s}^{-1}$

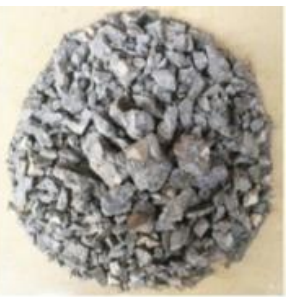

$104.58 \mathrm{~s}^{-1}$

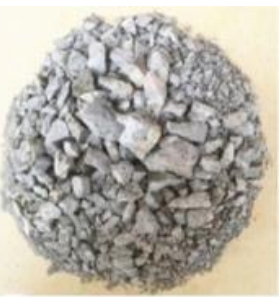

$111.23 \mathrm{~s}^{-1}$

(c)

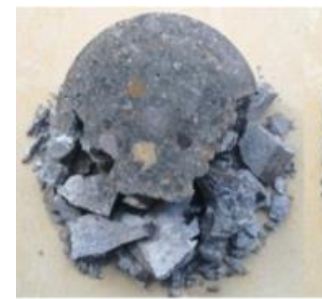

$50.89 \mathrm{~s}^{-1}$

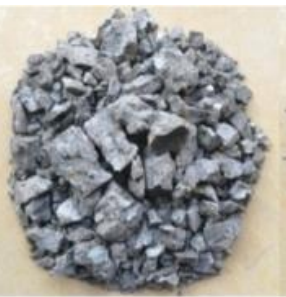

$60.77 \mathrm{~s}^{-1}$

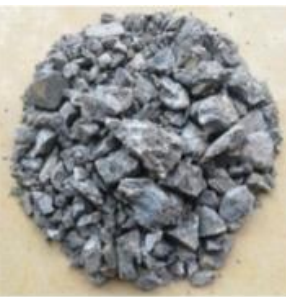

$78.39 \mathrm{~s}^{-1}$

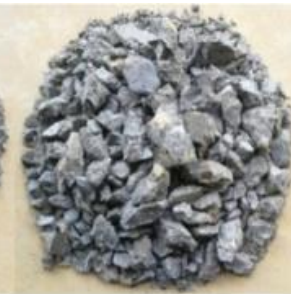

$89.04 \mathrm{~s}^{-1}$

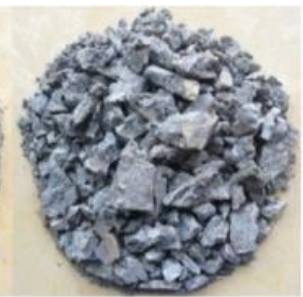

$97.65 \mathrm{~s}^{-1}$

(d)

Fig. 17 Typical failure modes of CNFC under different strain rates (a) CNFC01, (b) CNFC02, (c) CNFC03, (d) CNFC05 
The carbon nanofiber is of a nanometer-scale size, and possesses extremely high strength and fracture toughness while maintaining inherent excellent properties of carbon fillers. Through an SEM test of some CNFC specimen blocks after impact, and analysis of their microscopic morphology features, the modification mechanism of CNFs for concrete can be described as follows.

(1) Small size effect. The carbon nanofiber is a special nanomaterial, which can make use of its small size effect inside concrete to improve particle grading and general structural stability. Besides, the carbon nanofiber has an enormous specific surface area and super high surface activity. On the one hand, this facilitates hydration reaction of cement, resulting in a higher hydration degree and more hydration products. On the other hand, the nucleation and adsorption effects of nanomaterials allow molecular chains with CNFs as the core to form during the hydration process of cement (Fig.18), enhancing the integrity of gel of calcium silicate hydrated and concrete strength.

(2) Enhancement effect. The diameter of a single carbon nanofiber is usually 100-200 nm. When added into concrete, CNFs can fill the micropores and others defects inside the concrete matrix (Fig.19), reducing the number of harmful macropores in concrete, improving the original pore structure of concrete and strengthening compactness of the matrix. Besides, the CNFs can improve dynamic mechanical properties through structure because disordered and dense CNFs can form network structures similar to bridging to strengthen the connection between components, improve the interface structure between cement stones and the aggregate phase, and ease the tip stress concentration effect of microcracks inside concrete, improving its dynamic mechanical properties.

(3) Crack-arresting effect. Under impact loads, microcracks will initiate and propagate gradually inside concrete, and their propagation paths will go across disorderly distributed CNFs; or maybe a CNF already lies across a certain original crack from the beginning, and the ends of the CNF and the concrete matrix on both sides of the crack are properly bonded. When the impact load reaches a critical value, causing the CNF to bear force, part of the load will be shifted onto the CNF (Fig.20), and the CNF will bear part of the stress, delaying crack propagation and allowing the external load to increase without continuing to damage the concrete matrix. As the CNF can bear part of the load and the bonding force between itself and the matrix on both sides of the concrete is relatively strong, the impact load-bearing capability of the concrete is improved to some extent.
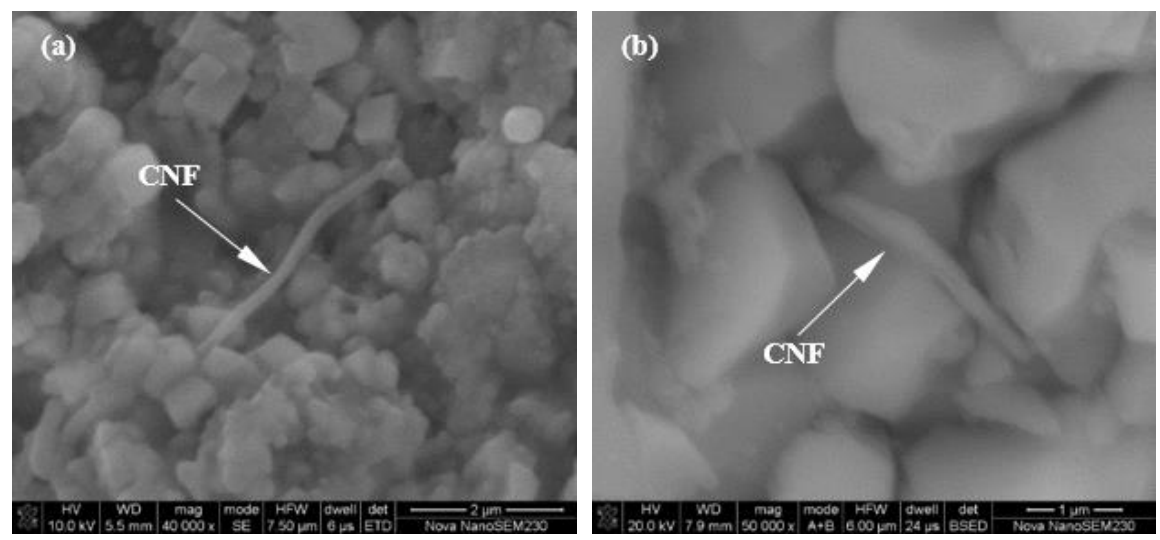

Fig. 18 CNF distribution in hydration product 

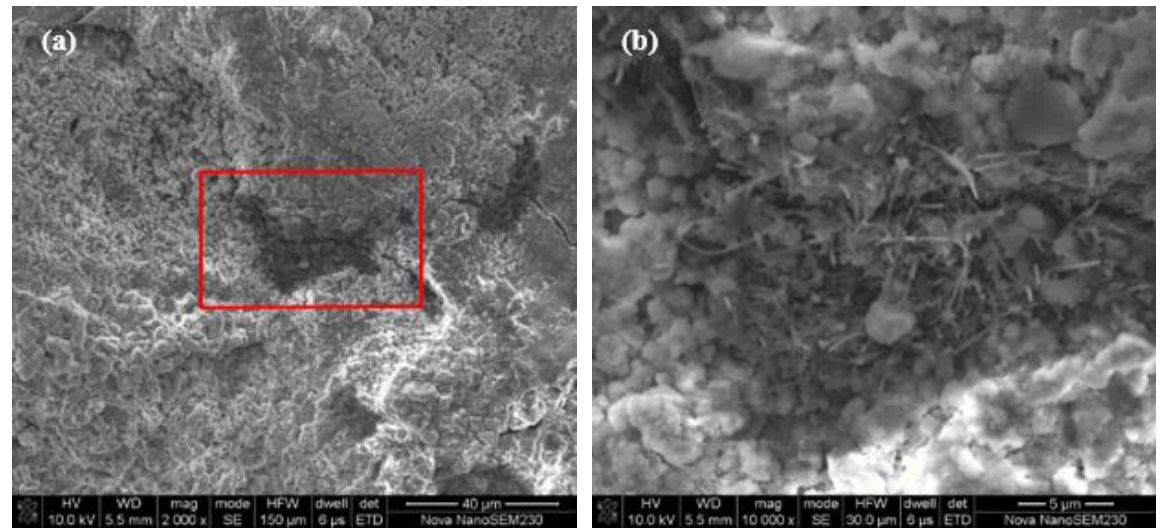

Fig.19 CNFs filling original defect (a) overall observation (b) local amplification
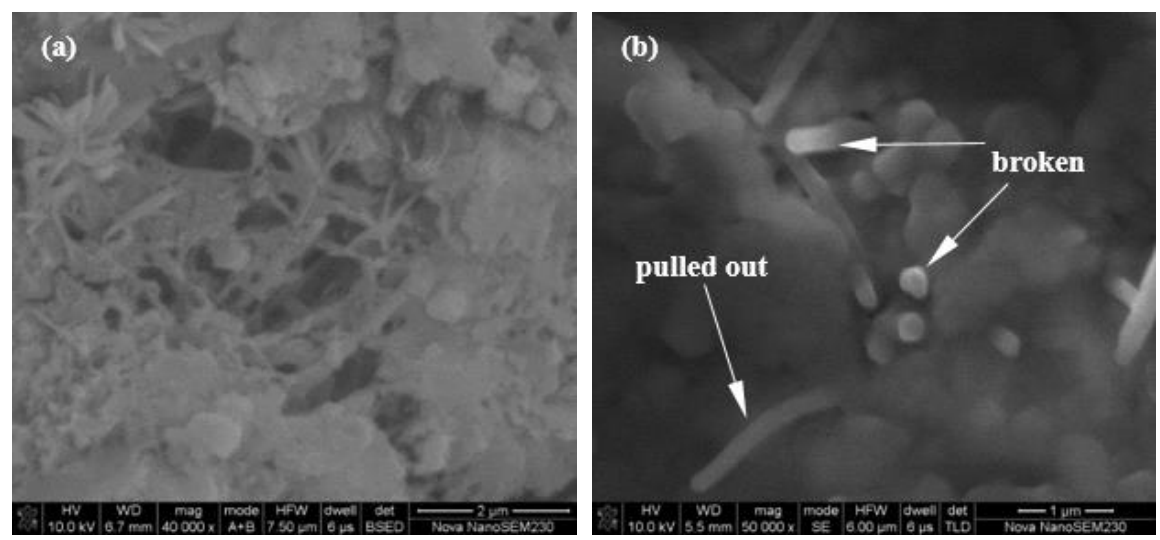

Fig.20 Crack-arresting effect of CNFs in the matrix (a) traversing crack (b) pulled out or broken

\subsection{Strengthening Effect of Strain Rate on Concrete}

Dynamic compressive strength, dynamic compression deformation, impact toughness and dynamic modulus of elasticity of concrete are all obviously sensitive to the loading rate (i.e. the strain rate). The mechanism of the strengthening effect of the strain rate on concrete is elaborated by using dynamic compressive strength as an example.

(1) As far as the free water in the pores of the specimen is concerned, the impact load caused an adhesion effect. The adhesion effect refers to the hindrance caused by the cohesive force of fluids to the relative movement between two flat boards with in-between adhesive fluids, and the faster the movement, the greater the force. The cracks filled with free water can be regarded as an adhesion model, so the free water inside the concrete specimen will hinder crack propagation. The greater the loading rate, the more obvious the hindrance. What's more, during impact loading, as the free water inside the concrete does not have enough time to spread, the generated water pressure will cancel part of the load, resulting in improvement of the dynamic compressive strength of the concrete.

(2) As far as the entire impact loading process is concerned, the specimen failure is influenced by the inertial restraint effect. Although the specimen only bears a dynamic compression load in the axial direction, which is a one-dimensional stress state macroscopically, for a big-size specimen with a diameter of $100 \mathrm{~mm}$, its stress points concentrate on the central part, that is, the central area of the specimen bears most of the load. As a result of the hoop effect, the edge of the specimen limits the horizontal deformation of the central area, which can be deemed as the edge applying some confining pressure to the central area. Besides, the greater the loading rate, the stronger the restraint effect, that is, the more obvious the confining pressure effect caused by the edge. Therefore, the concrete can bear more impact loads. The inertial restraint effect of the concrete specimen under an impact load converts a 
one-dimensional stress state into a one-dimensional strain state, causing a significant strain rate-strengthening effect for the dynamic compressive strength.

(3) As far as the cracks inside the specimen is concerned, the impact load affects the law of crack initiation and the crack propagation method. During impact loading, original cracks inside concrete do not have enough time to develop into through cracks, which causes new cracks to appear so as to dissipate external energy. The greater the loading rate, the more the initiated cracks and the more the energy needed, that is, the greater the impact loading the specimen can bear, the greater the dynamic compressive strength macroscopically. Besides, based on the theorem of impulse, as the action time of the impact loading is extremely short, the specimen does not have enough time to accumulate energy through deformation and can only cancel the external load through buffer stress. Therefore, the specimen's failure stress increases with the loading rate.

\section{Conclusion}

Here, impact load experiments were conducted by using the $100 \mathrm{~mm}$-diameter SHPB test device on a plain concrete specimen and CNFC specimens with volume fractions of $0.1 \%, 0.2 \%, 0.3 \%$ and $0.5 \%$ to systematically study their dynamic compressive mechanical characteristics, and analyze the evolution law of their dynamic compressive strength, dynamic compression deformation, impact toughness, dynamic modulus of elasticity and other metrics. Through these and the macro failure modes as well as the micro test results of the specimens, the evolution mechanism of the dynamic mechanical properties of concrete is elaborated from the perspectives of fiber incorporation and strain rate effect. The following conclusions can be drawn.

(1) The different volume fractions of CNFs all enhanced the dynamic compressive strength, dynamic compression deformation and impact toughness of the concrete to different degrees. The fraction for achieving the best dynamic compressive strength enhancement is $0.3 \%$, while only the volume fraction of $0.2 \%$ improved the dynamic modulus of elasticity.

(2) The dynamic compressive strength, impact toughness and dynamic modulus of elasticity of the plain concrete and the CNFCs all increased with the strain rate, with a significant linear correlation shown. Although the dynamic peak strain and the ultimate strain increased with the strain rate level, there was no significant linear correlation.

(3) Under the impact load, the plain concrete showed core failure only at a low strain rate, with the rest failure all being crushing failure. The failure for the CNFCs was mainly core failure and fragmentation failure, and under high strain rates, little did the fragmentation degree change even when the strain rate increased significantly.

(4) Adding a proper amount of CNFs can improve the original micro-pore structures inside the concrete, and produce a small size effect and enhancement and crack-arresting effects to strengthen the compactness of the matrix, thus improving the dynamic compressive mechanical properties of the concrete under impact loads.

\section{Author Contributions:}

Wei Xia: Conceptualization, Methodology, Data curation, Formal analysis, Writing-original draft;

Jinyu Xu: Project administration, Validation, Visualization, Investigation;

Liangxue Nie: Writing-reviewing and editing, Visualization.

Funding: This research was funded by THE NATIONAL NATURAL SCIENCE FOUNDATION OF CHINA, grant number 51208507 and 51378497.

Acknowledgments: The authors would like to thank the National Natural Science Foundation of China (under Grant No. 51208507 and No. 51378497) for the financial support.

Conflicts of Interest: There are no conflicts to declare. 


\section{Reference}

1 Liu J W, Wang C, Xiong G Q. Research on the preparation of rigid self-waterproofing concrete by using RAP and nano- $\mathrm{SiO}_{2}[\mathrm{~J}]$. Materials Reports, 2020, 34(08): 8090-8095.

2 Umar M, Fathima N, Mohammed M S H S, et al. Modified cement composites for protection against microbial induced concrete corrosion of marine structures[J]. Biocatalysis and Agricultural Biotechnology, 2019, 20: 101192.

3 Li Z. Durability and modification mechanism of nano-modified concrete[D]. Harbin Institute of Technology, 2017.

4 Hanumesh B M, Harish B A N, Ramana V. Influence of polypropylene fibres on recycled aggregate concrete[J]. Materials Today: Proceedings, 2018, 5(1): 1147-1155.

5 Zhang Y N, Li J C, Wang Q F, et al. Mechanism and experimental study on crack monitoring and repair of shape memory alloy intelligent concrete[J]. Chinese Journal of Solid Mechanics, 2020, 41(02): 170-181.

6 Zhao J X. Carbon nanofiber and it's applications[J]. Hi-Tech Fiber and Application, 2003, 28(2): 7-10

7 Wang B M, Zhang Y, Han Y, et al. Probe of carbon nanofibers reinforced cement-based composites[J]. Materials Reports, 2013(1): 144-146.

8 Sanchez F, Ince C. Microstructure and macroscopic properties of hybrid carbon nanofiber/silica fume cement composites[J]. Composites Science and Technology, 2009, 69(7): 1310-1318.

9 Sanchez F, Sobolev K. Nanotechnology in concrete--A review[J]. Construction and Building Materials, 2010, 24(11): 2060-2071.

10 Gao D. A Study on the new type of construction material--carbon nanofiber concrete[D]. Central South University, 2011.

11 Zhuang G F. Piezoresistive behavior of carbon nano-fiber concrete in split and bending tests[J]. World Bridges, 2012, 40(4): 69-72.

12 Yao B. Influence of environmental conditions on the piezoresistive effect of carbon nanofiber concrete[D]. Harbin Institute of Technology, 2013.

13 Maria S. Konsta-Gdoutos, Chrysoula A. Aza. Self sensing carbon nanotube (CNT) and nanofiber (CNF) cementitious composites for real time damage assessment in smart structures[J]. Cement and Concrete Composites, 2014, 53: 162-169.

14 Meng W, Khayat K H. Effect of graphite nanoplatelets and carbon nanofibers on rheology, hydration, shrinkage, mechanical properties, and microstructure of UHPC[J]. Cement and Concrete Research, 2018, 105: 64-71.

15 Zhang X. Study on carbon nano-fiber modified hot mix asphalt concrete[J]. Journal of Wuhan University of Technology (Transportation Science and Engineering), 2016, 40(2): $335-338$.

16 Wang L F, Lin X. Mechanical properties and micromechanism of concrete modified by carbon nanofibers[J]. China Concrete and Cement Products, 2020(01): 51-54. 
17 Hao Y, Hao H. Dynamic compressive behaviour of spiral steel fibre reinforced concrete in split Hopkinson pressure bar tests[J]. Construction and Building Materials, 2013, 48(48): 521-532.

18 Ren W, Xu J. Fractal Characteristics of Concrete Fragmentation under Impact Loading[J]. Journal of Materials in Civil Engineering, 2016, 29(4): 04016244.

19 Sun X, Zhao K, Li Y, et al. A study of strain-rate effect and fiber reinforcement effect on dynamic behavior of steel fiber-reinforced concrete[J]. Construction and Building Materials, 2018, 158: 657-669.

20 Xu J Y, Zhao D H, Fan F L. Dynamic characteristics of fiber reinforced concrete[M]. Xi'an: Northwest University of Technology Press, 2013.

21 Chen X, Ge L, Zhou J, et al. Experimental study on split Hopkinson pressure bar pulse-shaping techniques for concrete[J]. Journal of Materials in Civil Engineering, 2015, 28(5): 04015196.

22 Nie L X, Xu J Y, Wang H W, et al. Degradation of dynamic mechanical properties and the microstructure of concrete after acid attack[J]. Journal of Vibration and Shock, 2017, 36(14): 126-132.

23 Ren W, Xu J, Su H. Dynamic compressive behavior of basalt fiber reinforced concrete after exposure to elevated temperatures[J]. Fire and Materials, 2016, 40(5): 738-755.

24 Song L, Hu S S. Two wave and three wave method in SHPB data processing[J]. Explosion and Shock Waves, 2005(04): 368-373.

25 Hou X, Cao S, Zheng W, et al. Experimental study on dynamic compressive properties of fiber-reinforced reactive powder concrete at high strain rates[J]. Engineering Structures, 2018, 169:119-130.

26 Li S, Lajtai E Z. Modeling the stress-strain diagram for brittle rock loaded in compression[J]. Mechanics of Materials, 1998, 30(3): 243-251. 


\section{Figures}

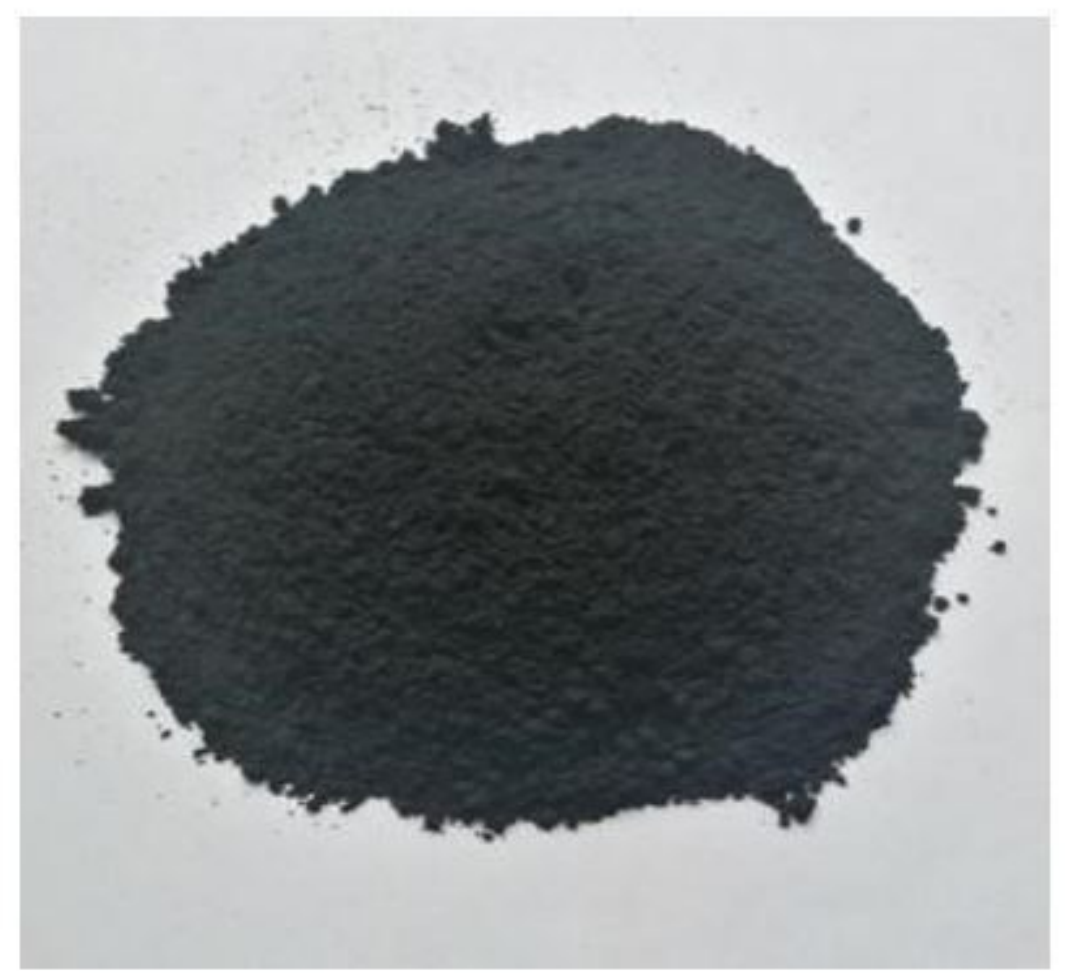

Figure 1

Carbon nanofibers

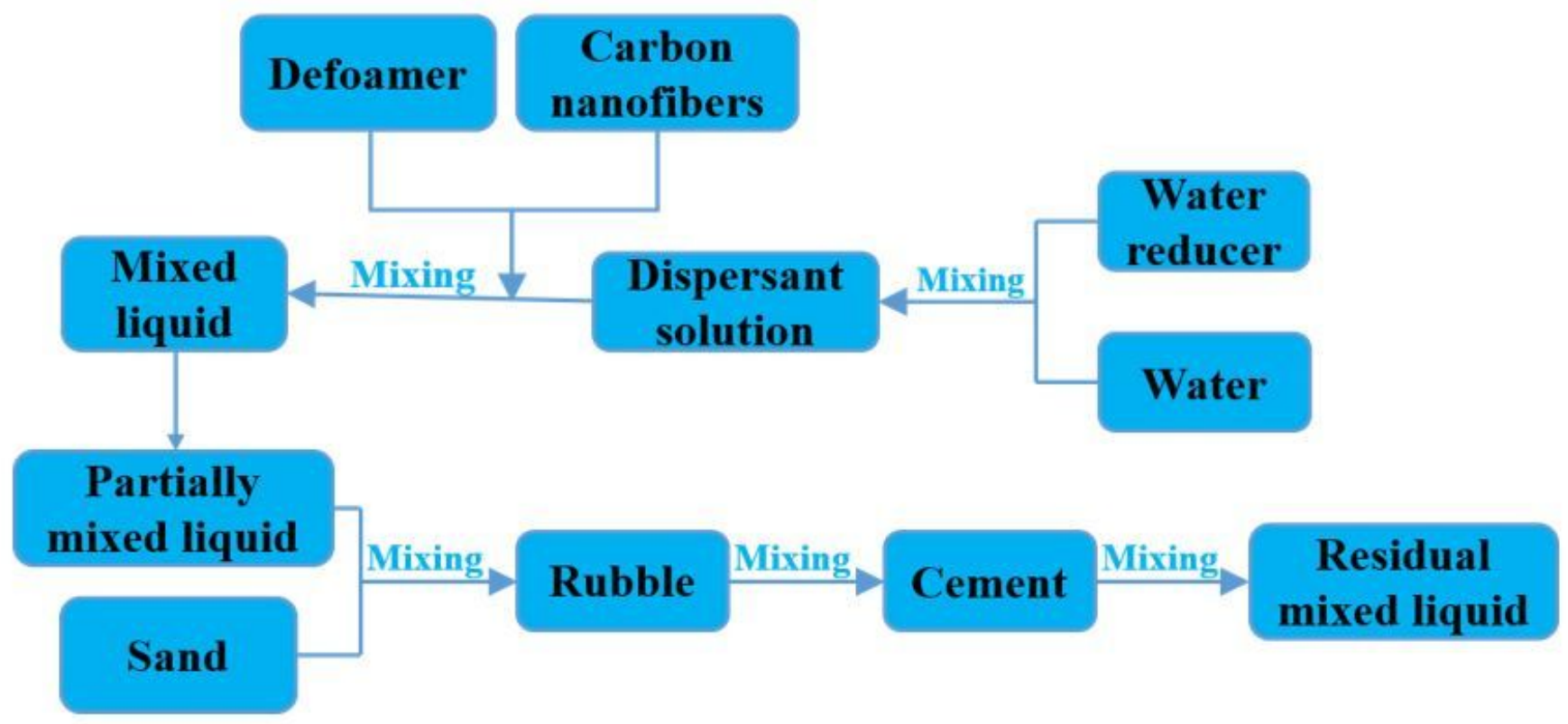

Figure 2 
Mechanism for pouring of CNFC group samples

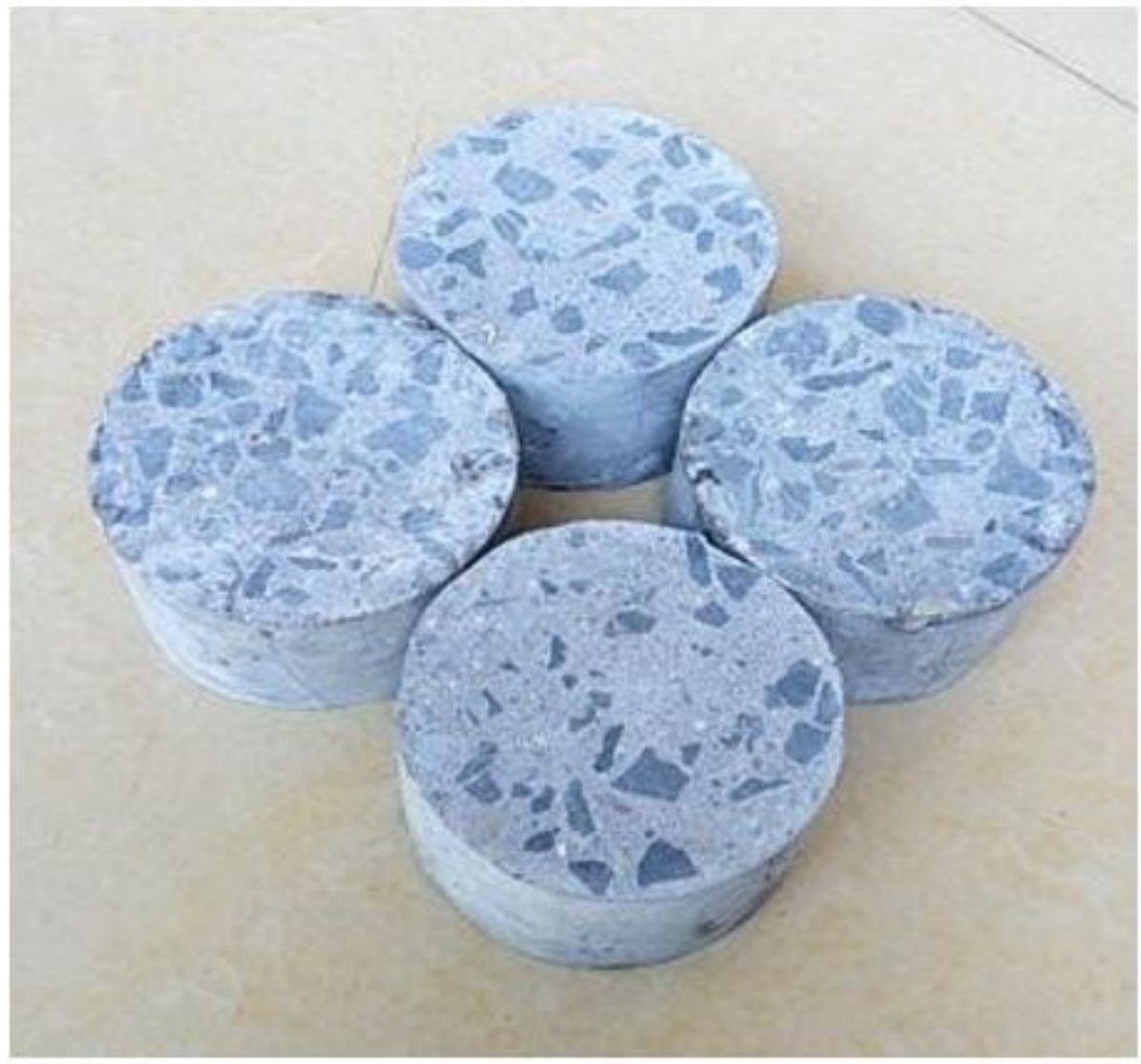

Figure 3

Processed short cylinder samples 


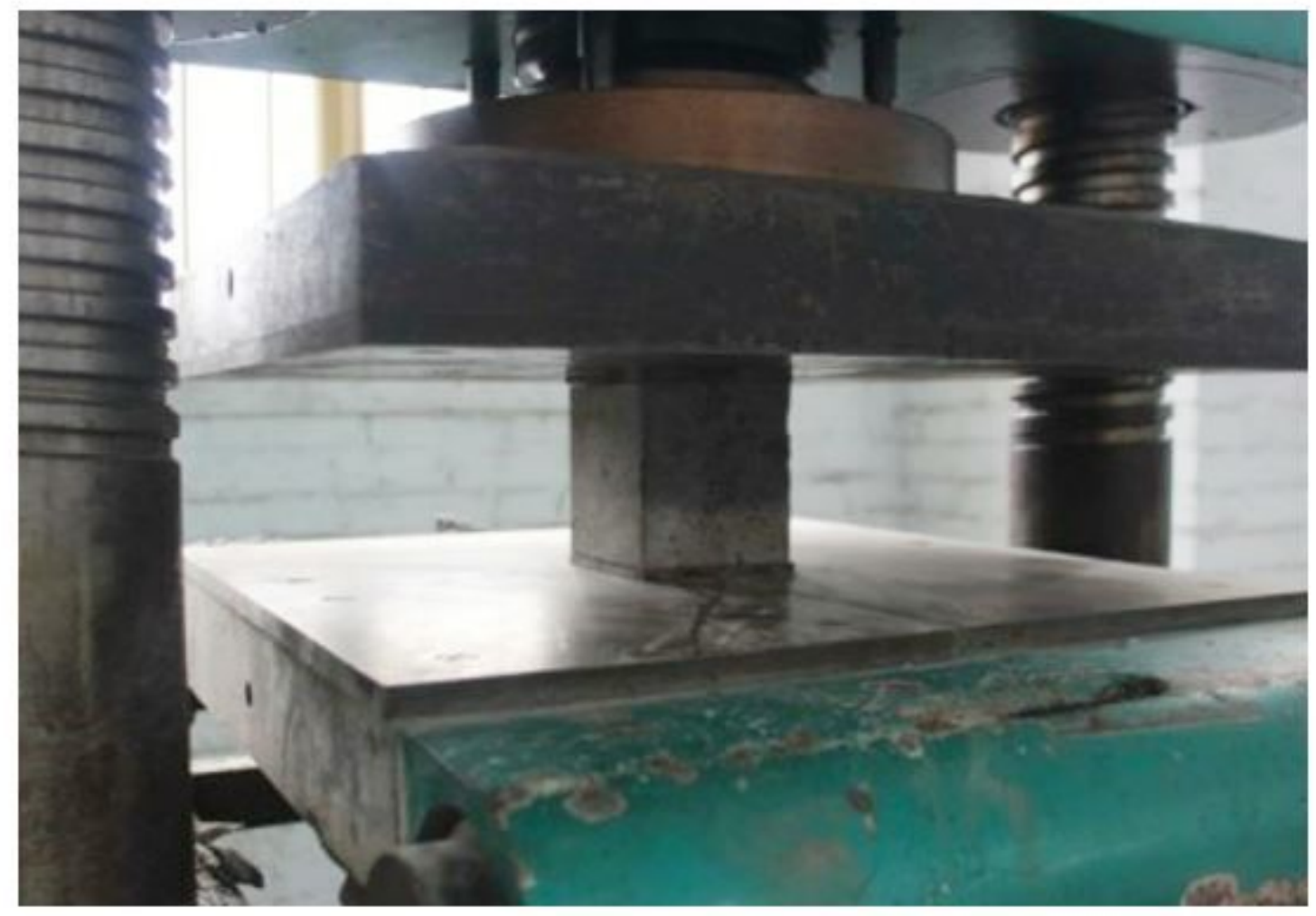

Figure 4

Static compression test

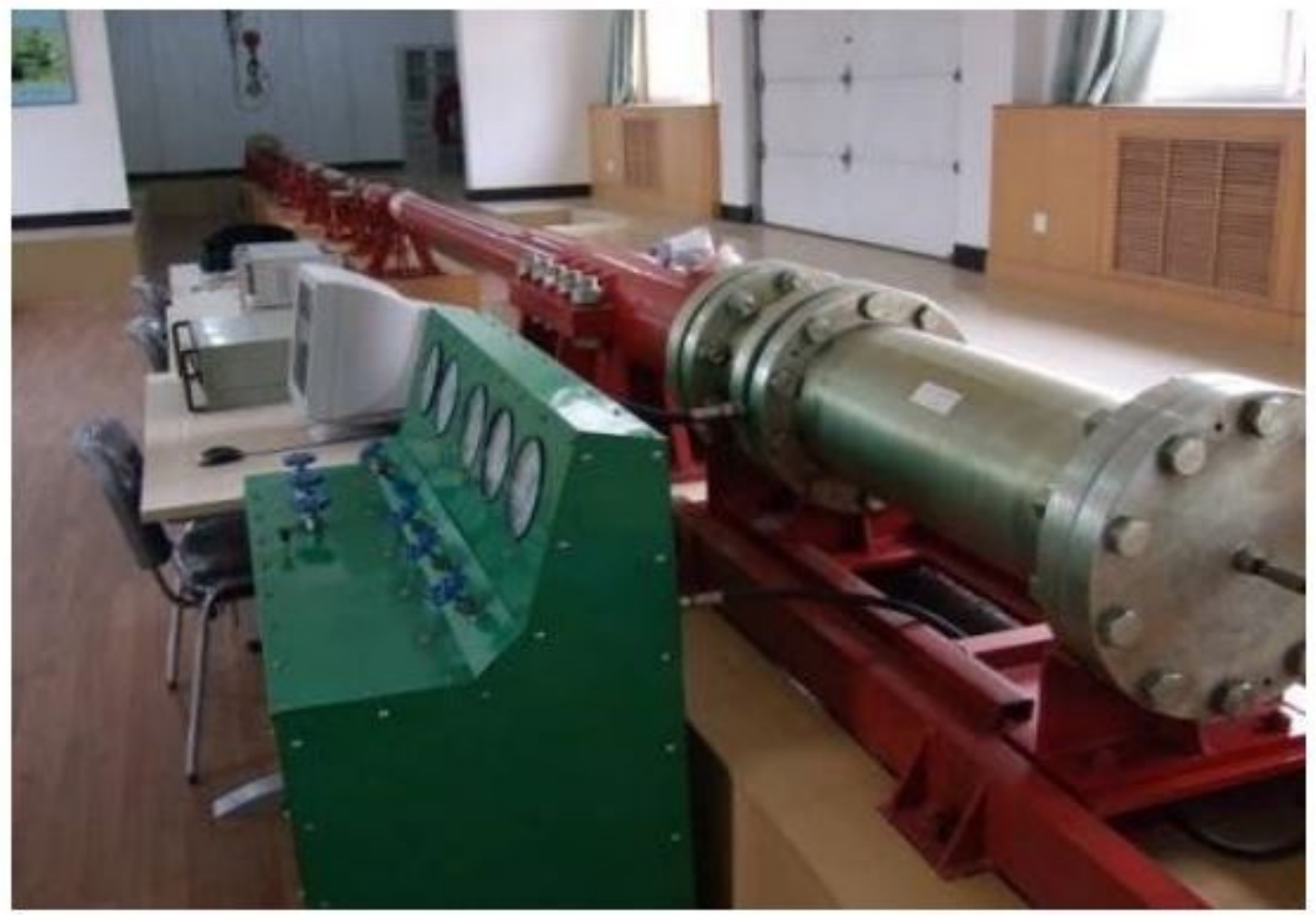

Figure 5 


\section{Strain}

Incident bar gauge $\quad A_{1}$ Sample $A_{2}$ gauge Transmission bar

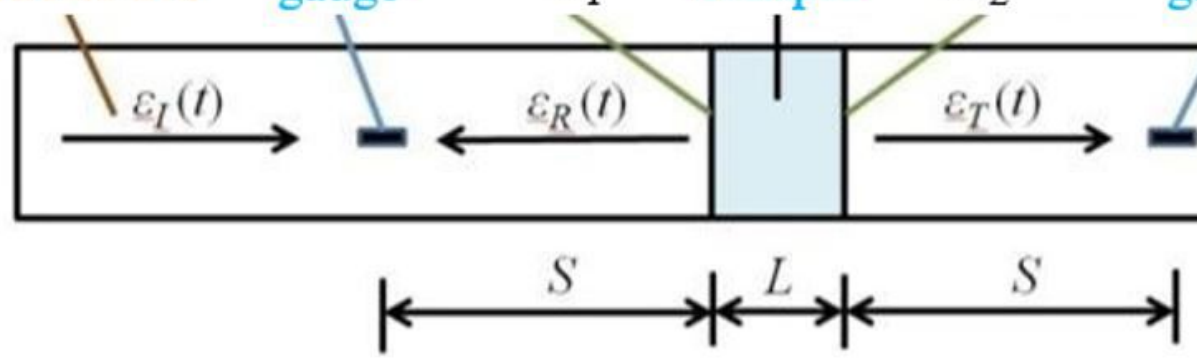

Figure 6

Stress wave propagation at interfaces

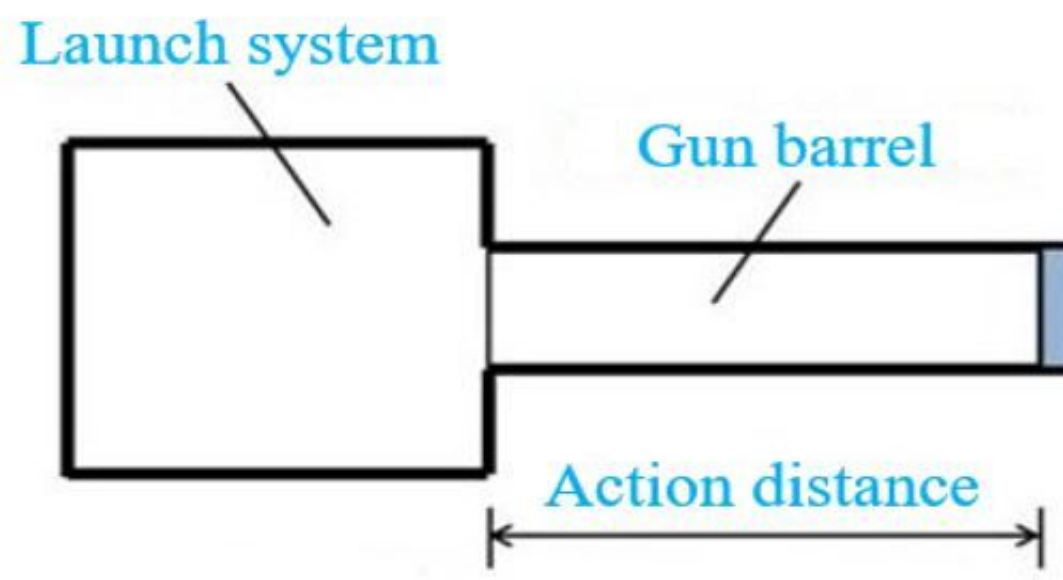

Figure 7

Control of bullet impact speed 


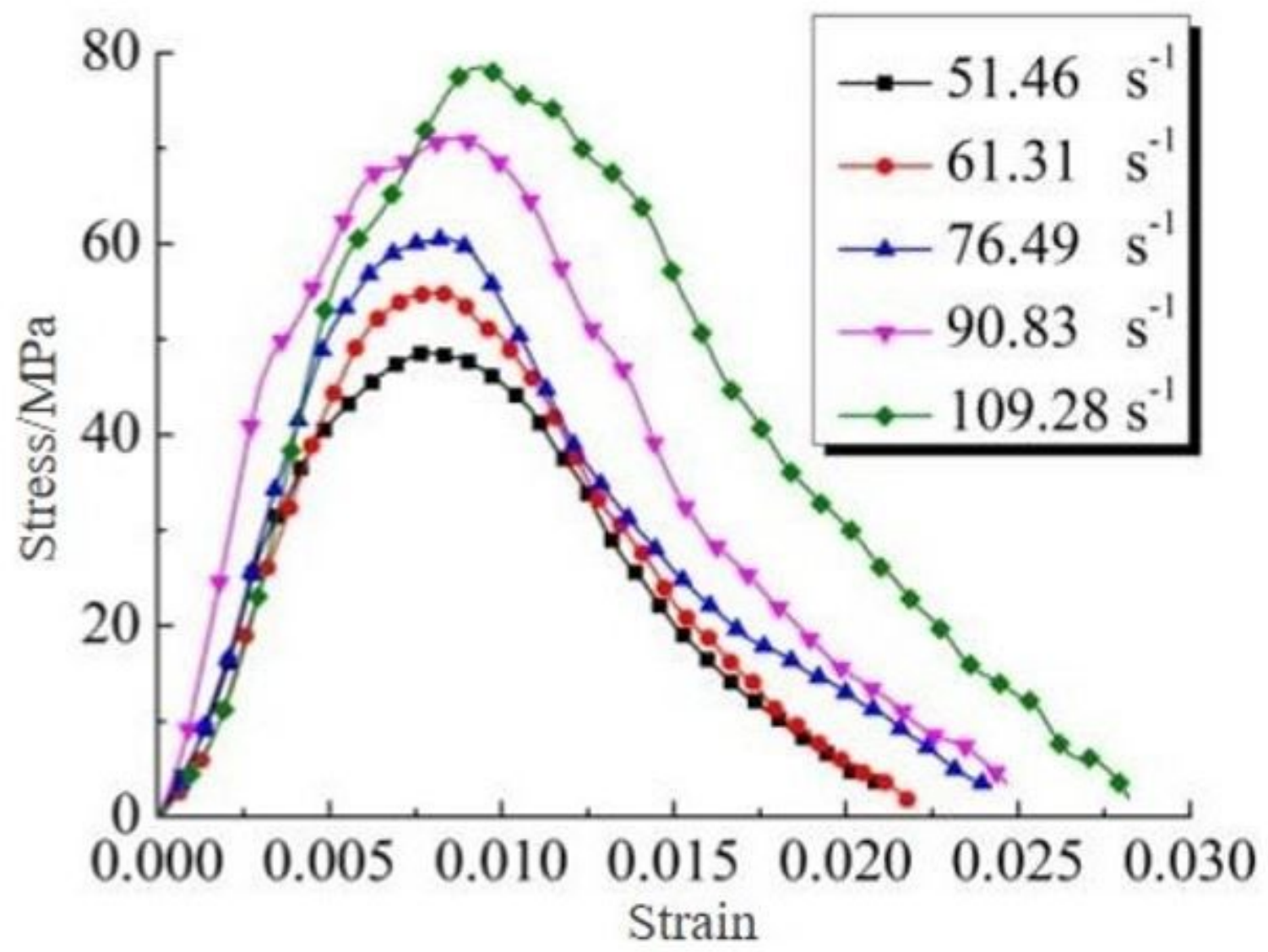

Figure 8

Stress-Strain curve of plain concrete under different strain rates 

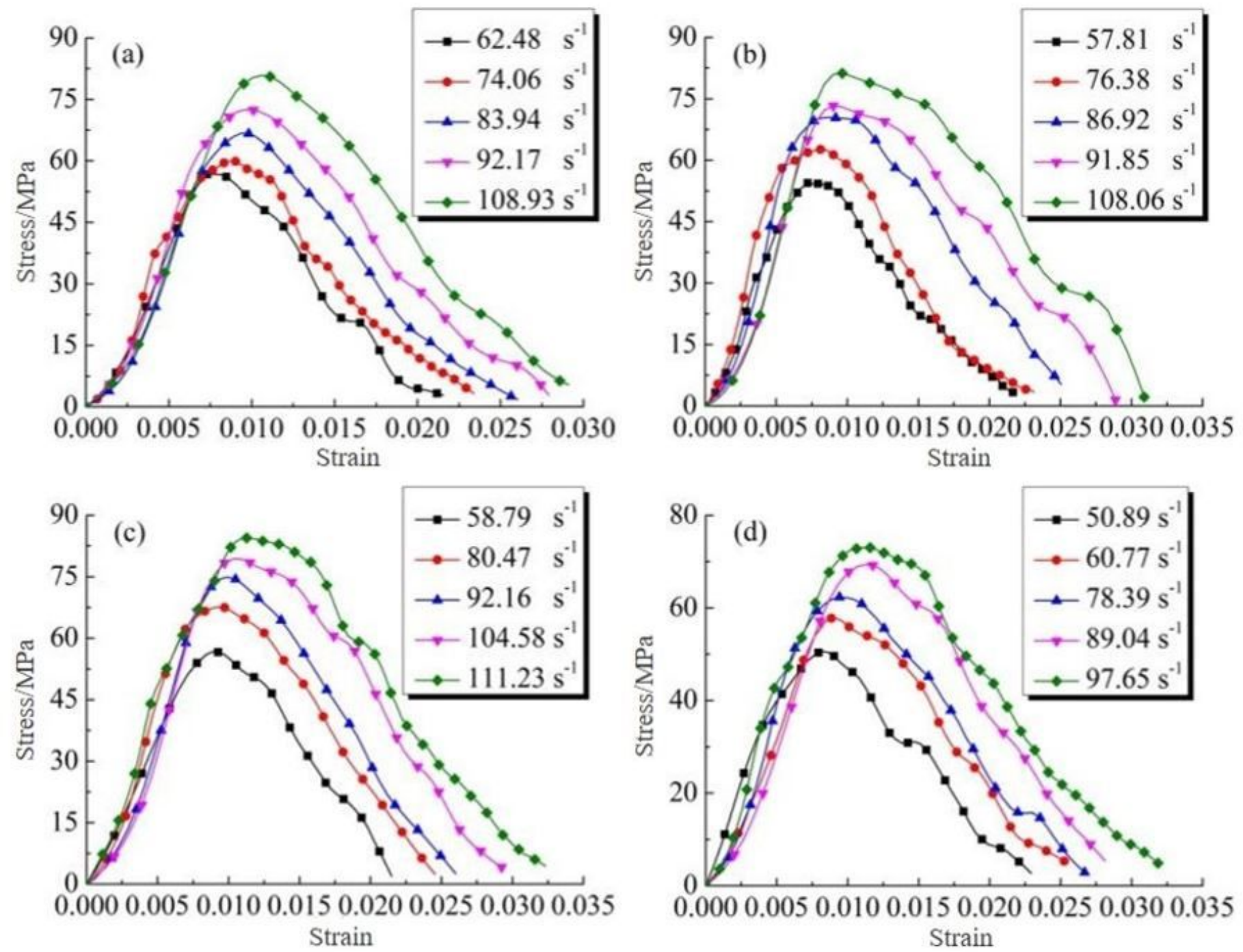

Figure 9

Stress-Strain curves of carbon nanofibers reinforced concrete under different strain rates (a)CNFC01, (b)CNFC02, (c)CNFC03, (d)CNFC05 


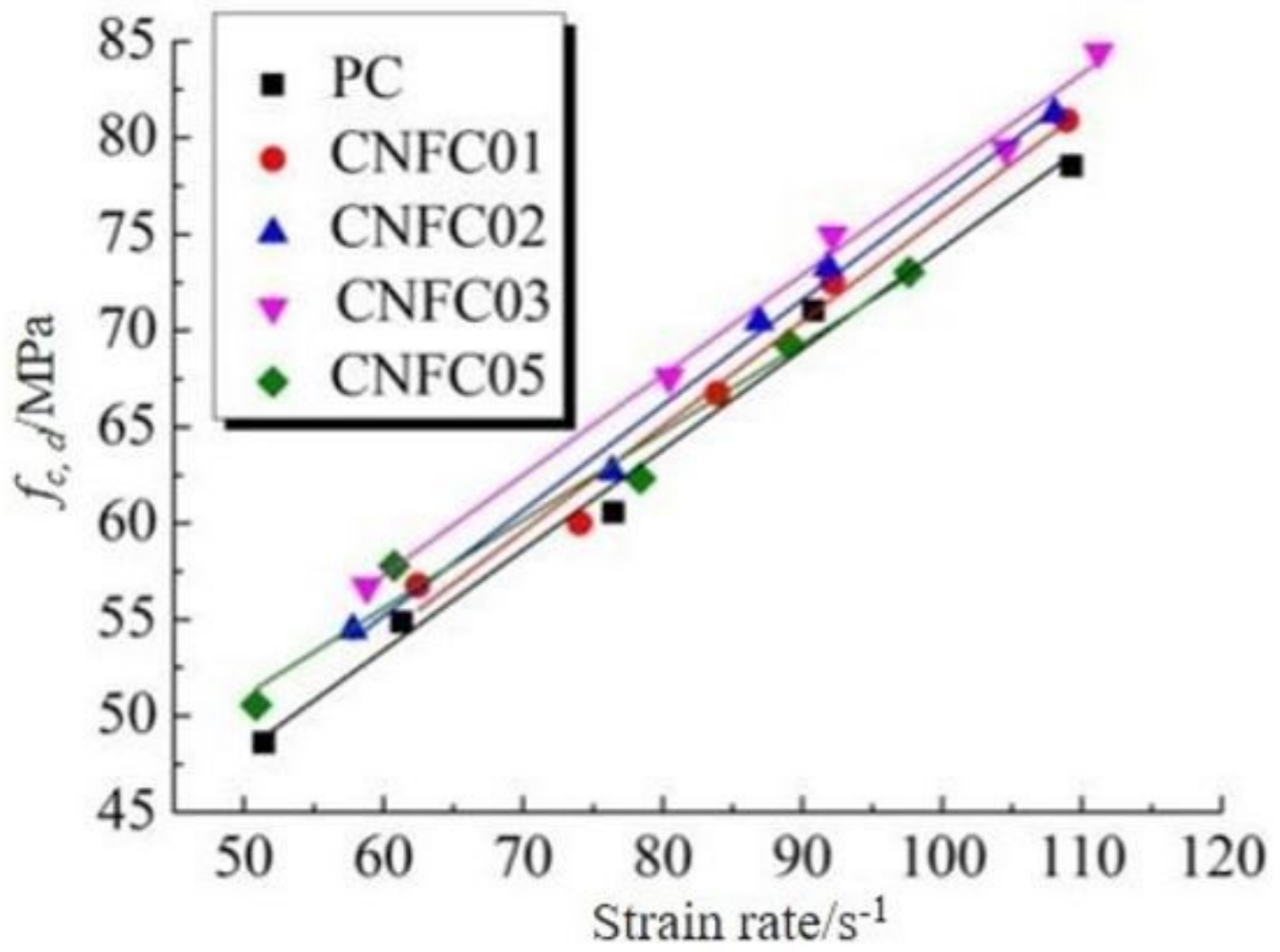

Figure 10

Dynamic compressive strength of concrete under different strain rates 


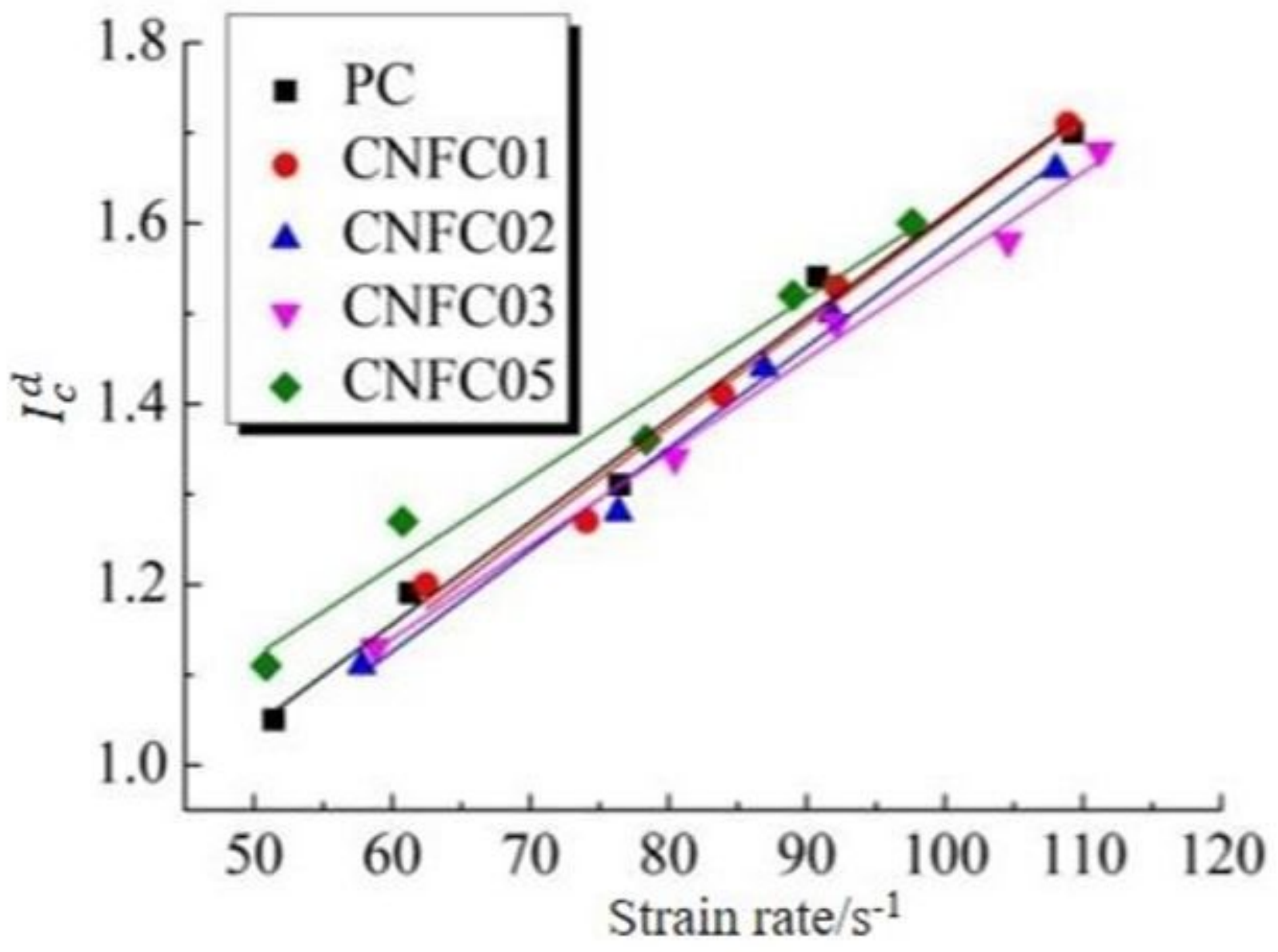

Figure 11

Dynamic strength growth factor of concrete under different strain rates 


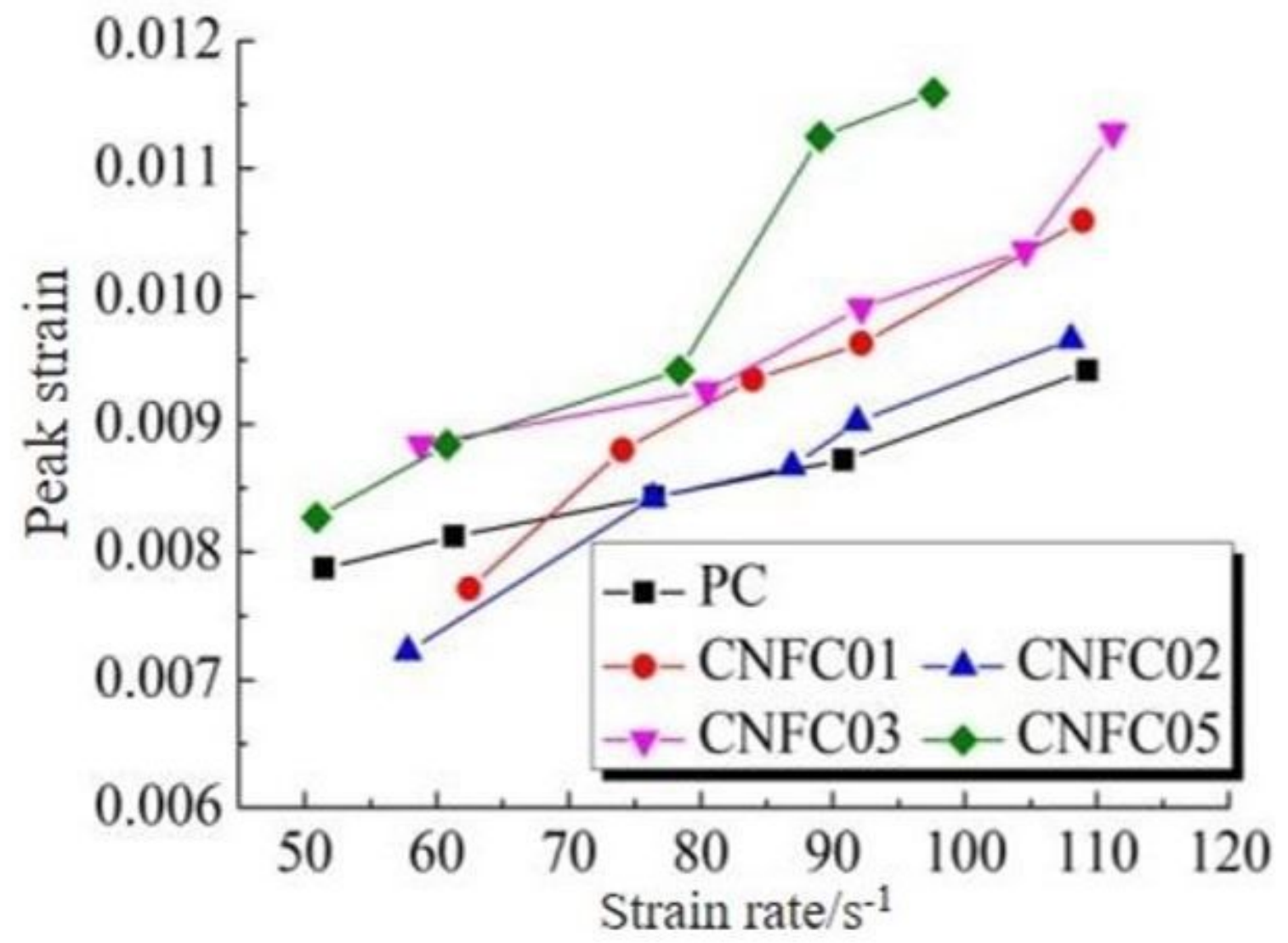

Figure 12

Dynamic peak strain of concrete under different strain rates 


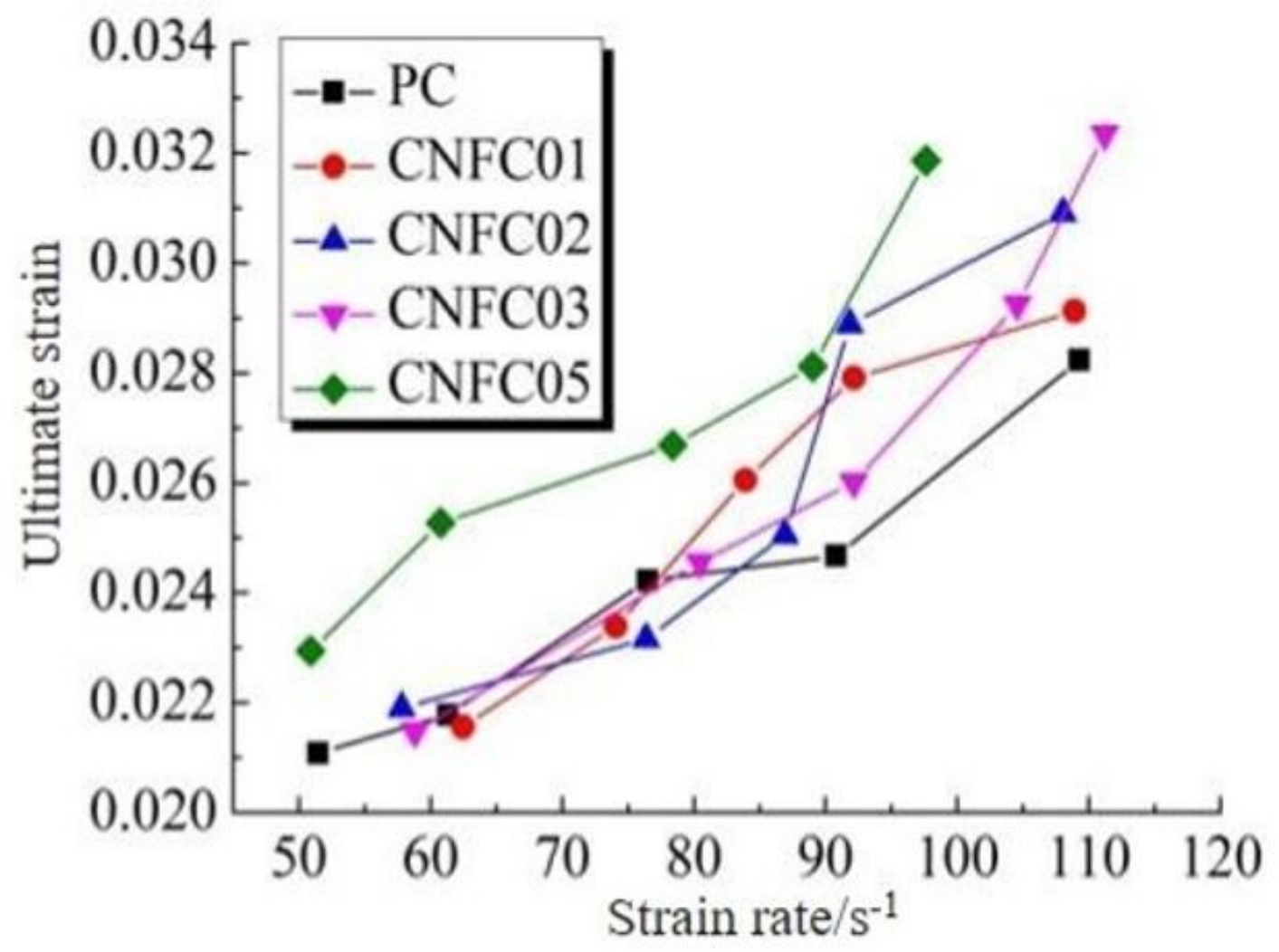

Figure 13

Dynamic ultimate strain of concrete under different strain rates 


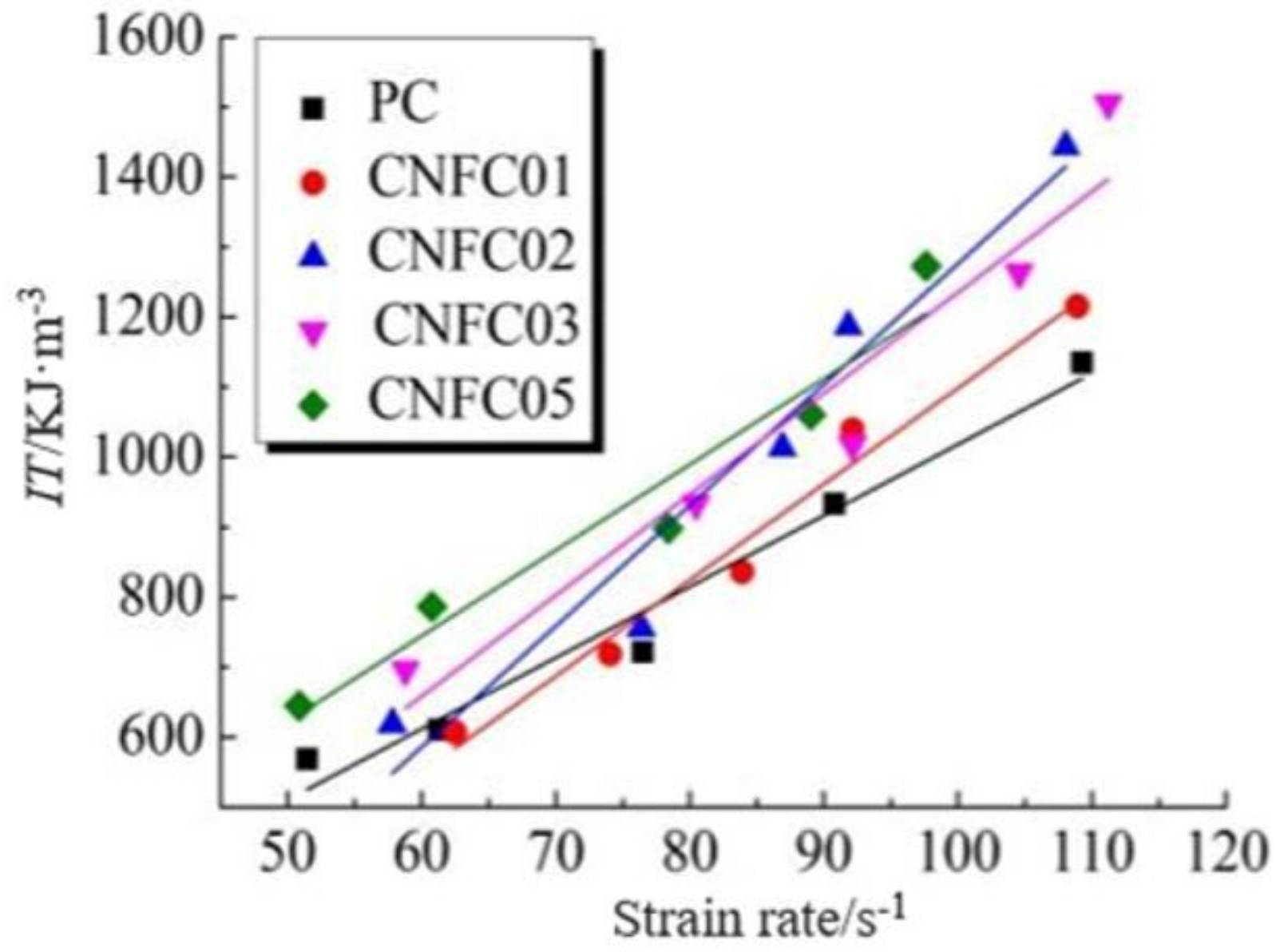

Figure 14

Impact toughness of concrete under different strain rates 


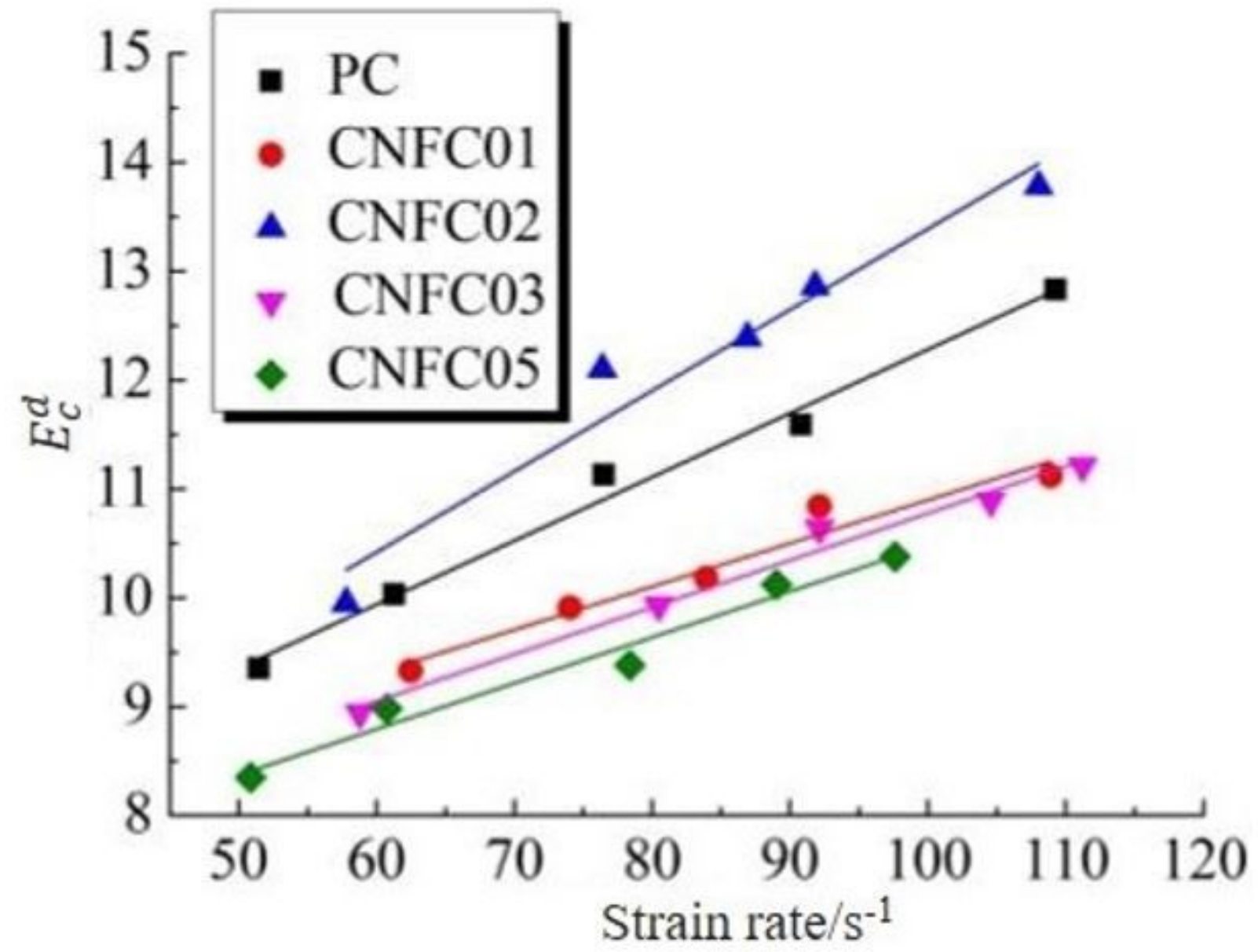

Figure 15

Dynamic modulus of elasticity of concrete under different strain rates

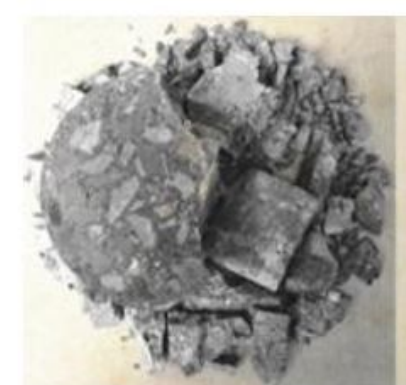

$51.46 \mathrm{~s}^{-1}$

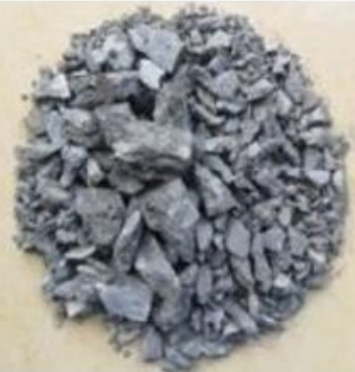

$61.31 \mathrm{~s}^{-1}$

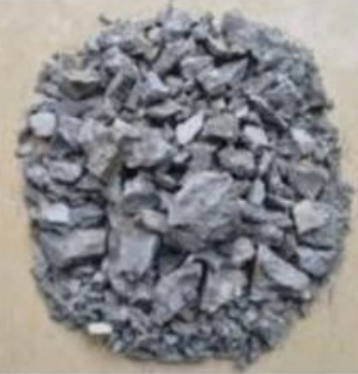

$76.49 \mathrm{~s}^{-1}$

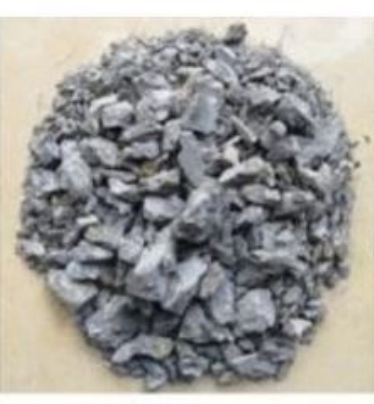

$90.83 \mathrm{~s}^{-1}$

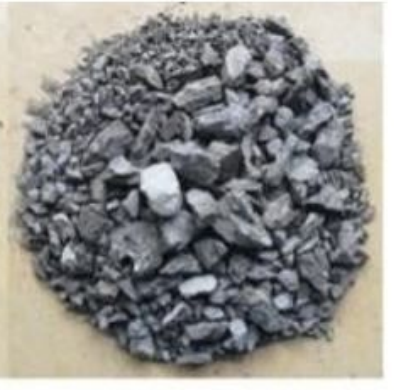

$109.28 \mathrm{~s}^{-1}$

Figure 16

Typical failure mode of plain concrete under different strain rates 


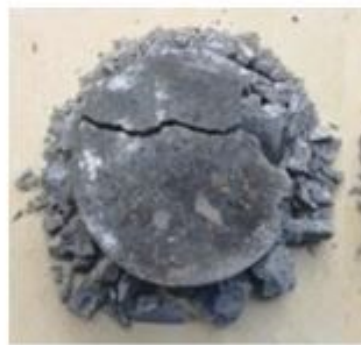

$62.48 \mathrm{~s}^{-1}$

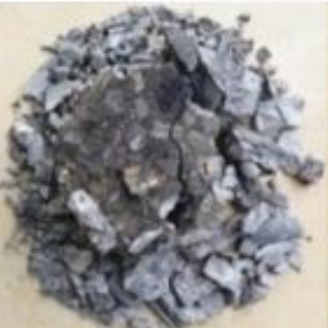

$74.06 \mathrm{~s}^{-1}$

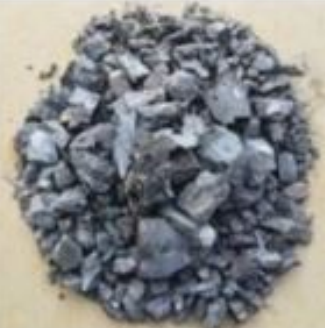

$83.94 \mathrm{~s}^{-1}$

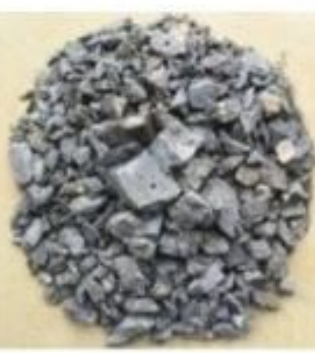

$92.17 \mathrm{~s}^{-1}$

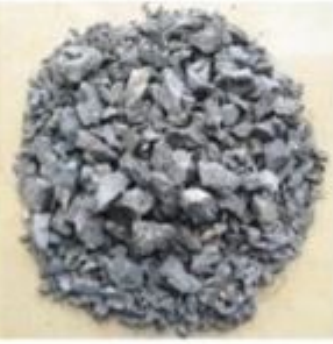

$108.93 \mathrm{~s}^{-1}$

(a)

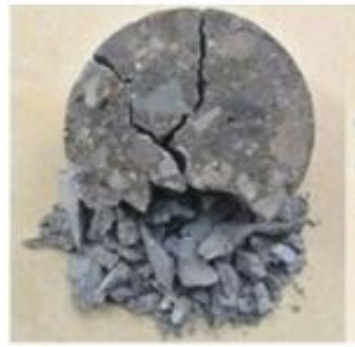

$57.81 \mathrm{~s}^{-1}$

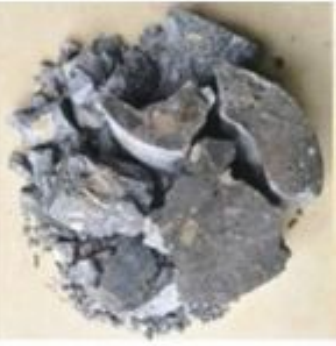

$76.38 \mathrm{~s}^{-1}$

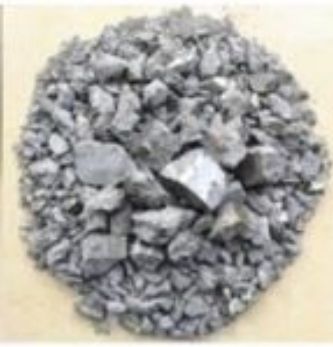

$86.92 \mathrm{~s}^{-1}$

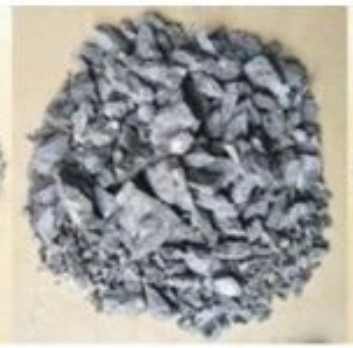

$91.85 \mathrm{~s}^{-1}$

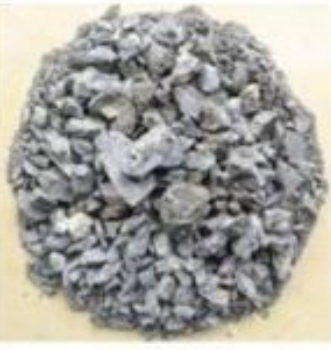

$108.06 \mathrm{~s}^{-1}$

(b)

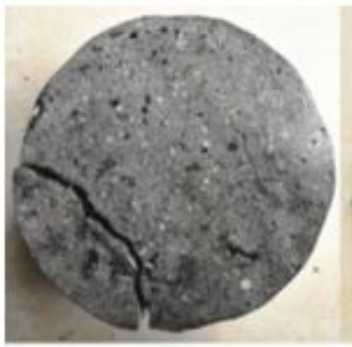

$58.79 \mathrm{~s}^{-1}$

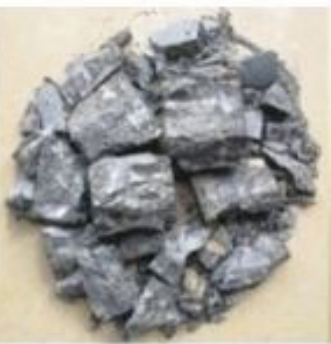

$80.47 \mathrm{~s}^{-1}$

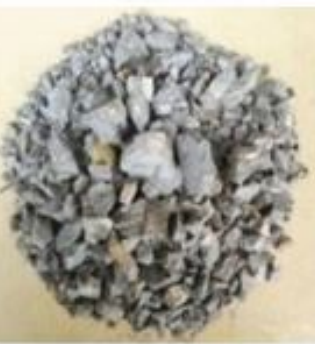

$92.16 \mathrm{~s}^{-1}$

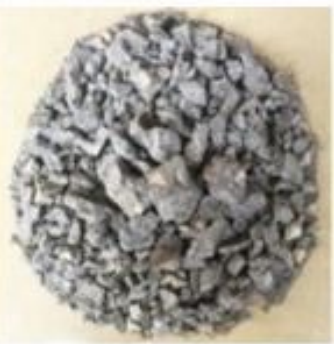

$104.58 \mathrm{~s}^{-1}$

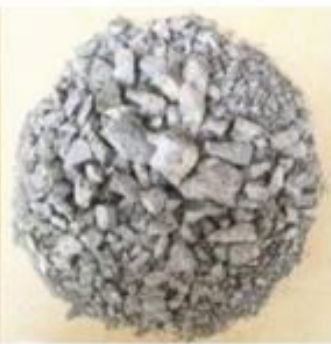

$111.23 \mathrm{~s}^{-1}$

(c)

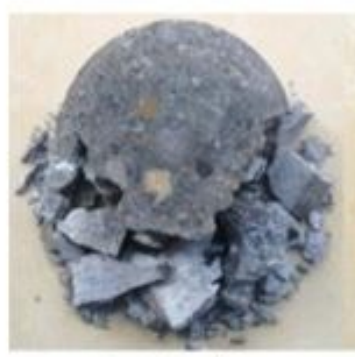

$50.89 \mathrm{~s}^{-1}$

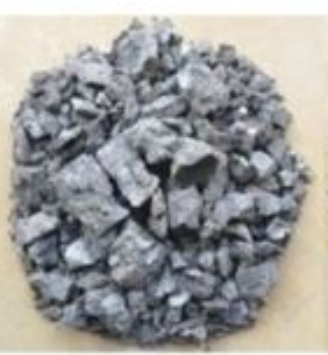

$60.77 \mathrm{~s}^{-1}$

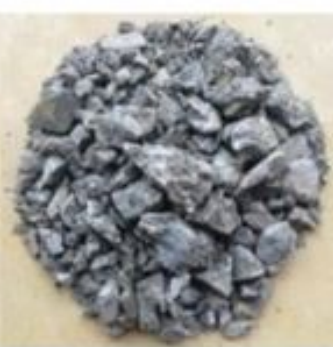

$78.39 \mathrm{~s}^{-1}$

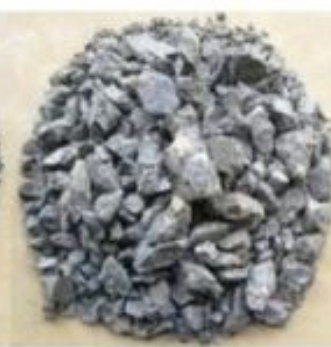

$89.04 \mathrm{~s}^{-1}$

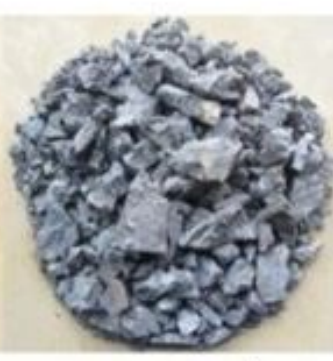

$97.65 \mathrm{~s}^{-1}$

(d)

\section{Figure 17}

Typical failure modes of CNFC under different strain rates (a) CNFC01, (b) CNFC02, (c) CNFC03, (d) CNFC05 

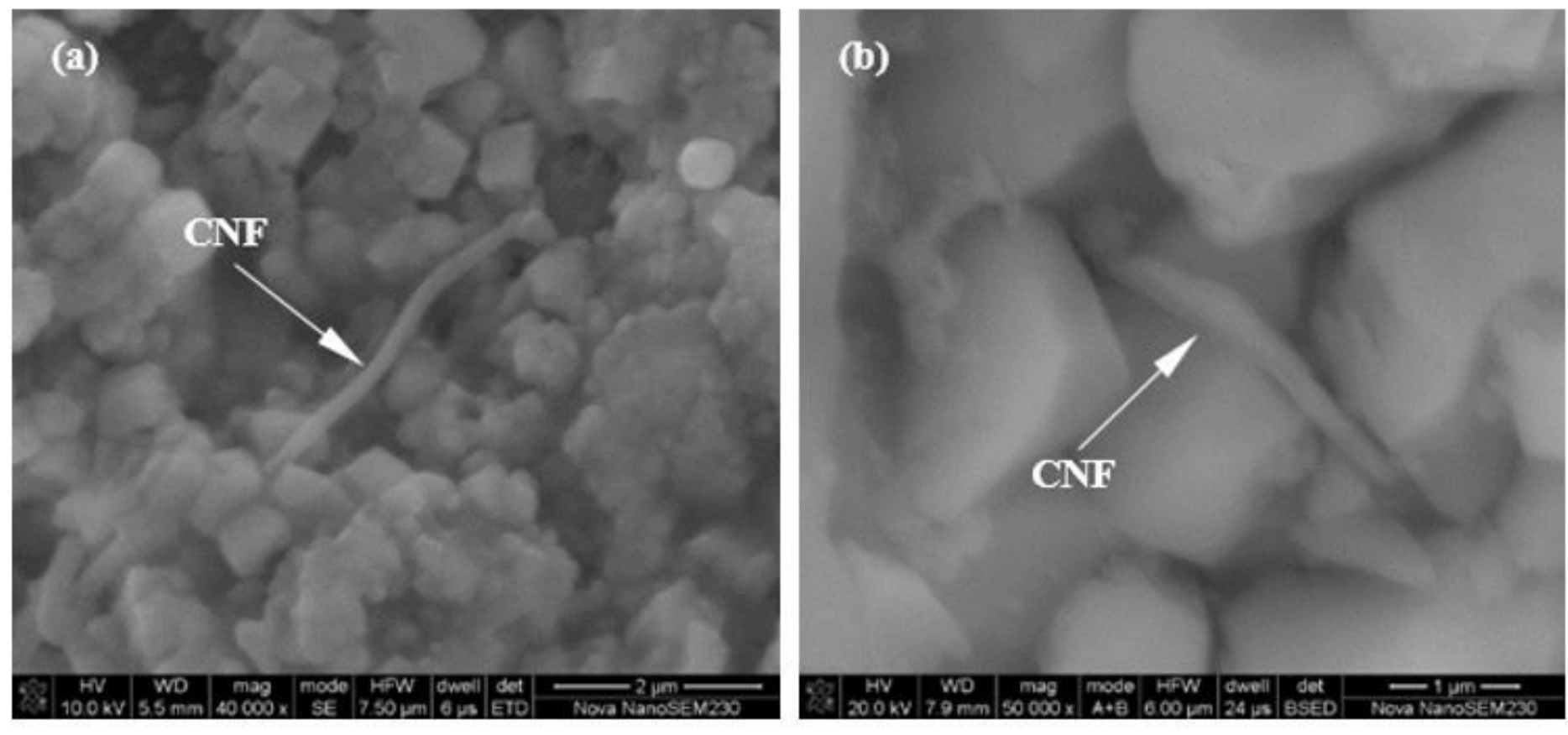

\section{Figure 18}

CNF distribution in hydration product
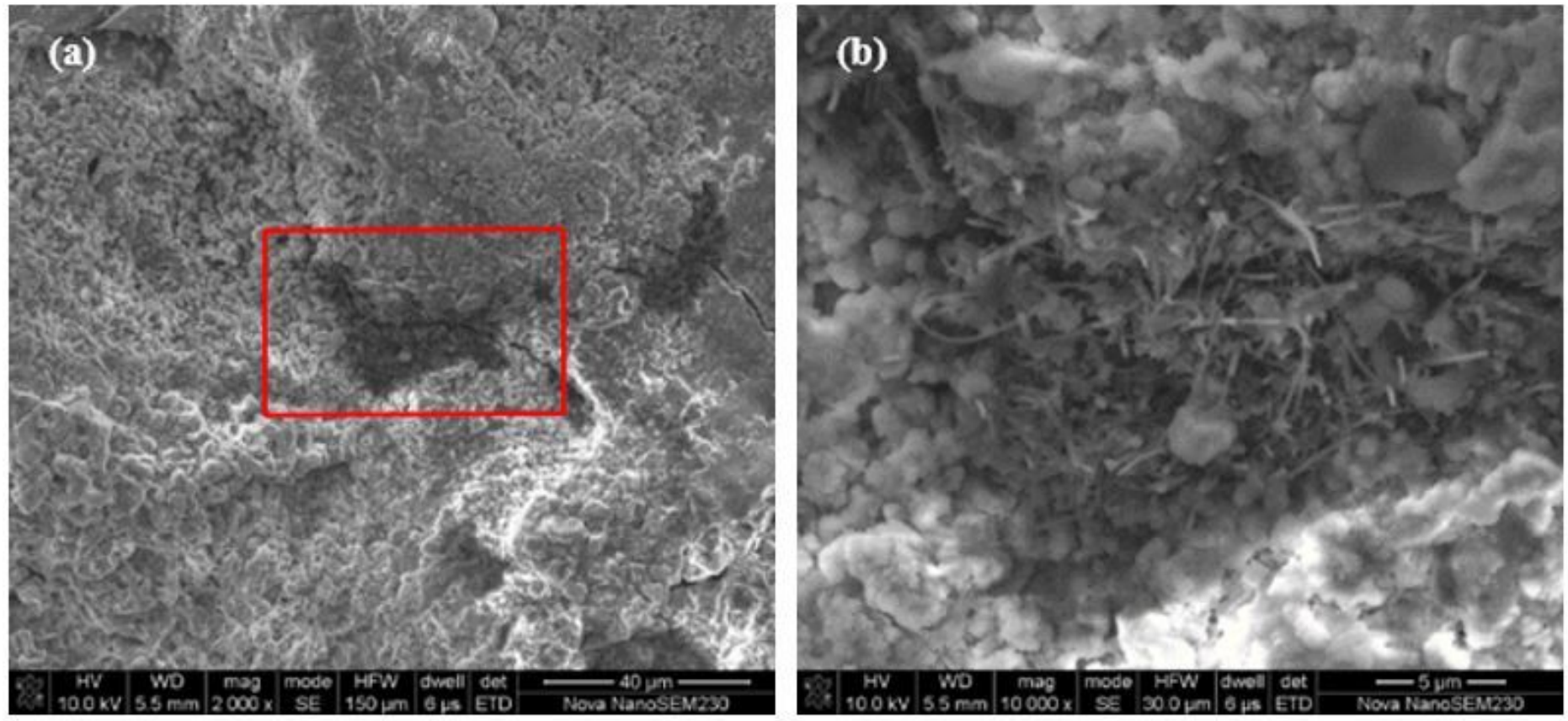

\section{Figure 19}

CNFs filling original defect (a) overall observation (b) local amplification 

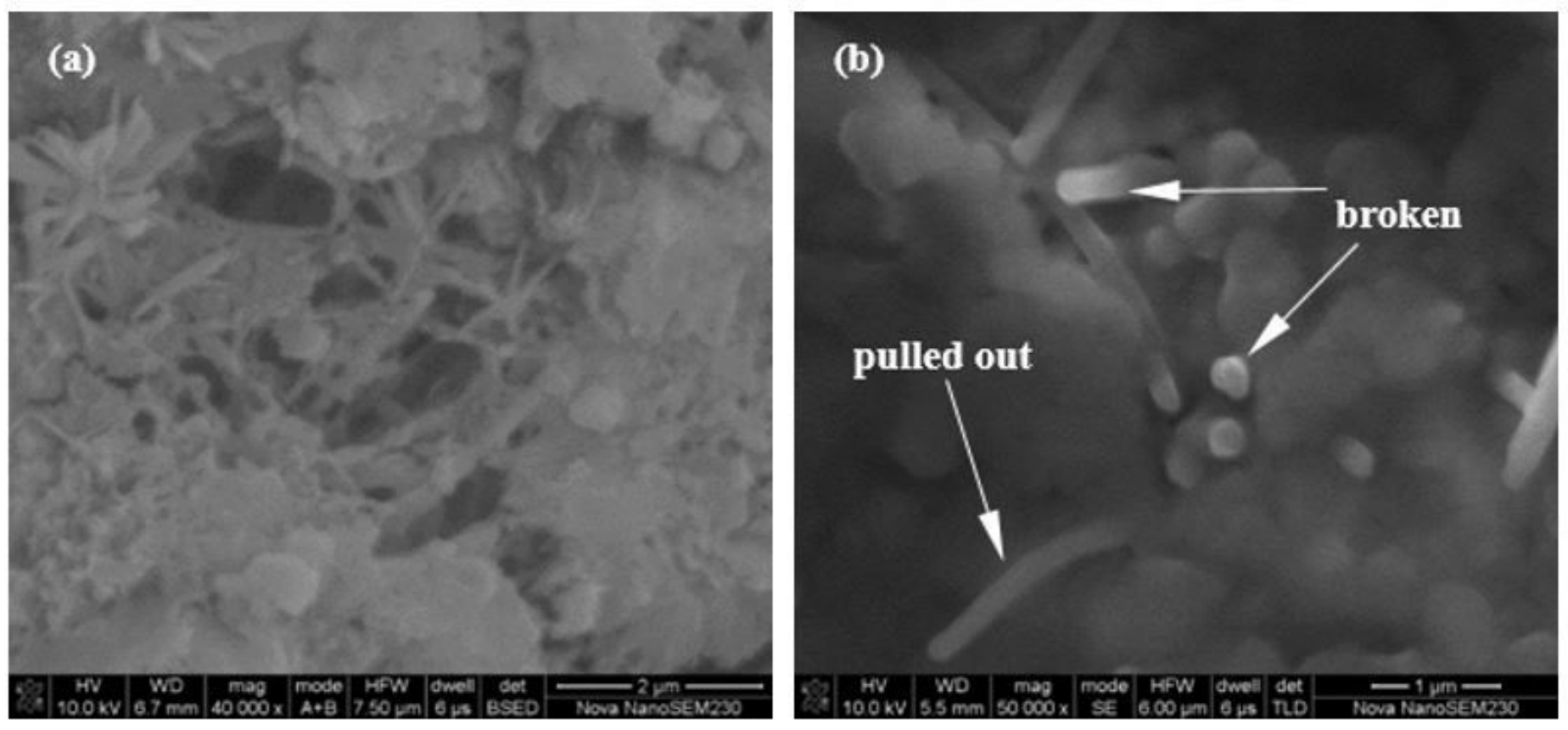

Figure 20

Crack-arresting effect of CNFs in the matrix (a) traversing crack (b) pulled out or broken 